\title{
A versatile Pt-Ce6 nanoplatform as catalase nanozyme and NIR-II photothermal agent for enhanced PDT/PTT tumor therapy
}

\author{
Qing $\mathrm{Chen}^{1 \dagger}$, Su $\mathrm{He}^{1 \dagger}$, Fangjun Zhang ${ }^{1}$, Fengzhi Cui ${ }^{3}$, Jianhua Liu ${ }^{3}$, Man Wang ${ }^{1}$, Dongmei Wang ${ }^{1}$, \\ Zhigang Jin ${ }^{1 *}$ and Chunxia $\mathrm{Li}^{1,2^{*}}$
}

\begin{abstract}
The hypoxic nature of solid tumors has severely negative effects on oxygen-based photodynamic therapy. In this study, we used porous Pt nanoparticles as a catalase (CAT) nanozyme, the second near-infrared (NIR-II) region photothermal transition agents (PTAs), and carriers of photosensitizer chlorin e6 (Ce6) to synthesize a composite nanosystem Pt-Ce6. In this system, Pt-Ce6 can continuously and stably decompose $\mathrm{H}_{2} \mathrm{O}_{2}$ into oxygen, thereby alleviating tumor hypoxia and improving the effect of photodynamic therapy (PDT). With $650 \mathrm{~nm}$ illumination, the reactive oxygen species (ROS) produced by Ce6 will decrease the mitochondrial membrane potential (MMP, $\Delta \Psi_{\mathrm{m}}$ ) to release cytochrome c (Cyt-c) from the mitochondria into the cytoplasm, eventually leading to mitochondrial-mediated cellular apoptosis during the PDT process. In addition, Pt-Ce6 has good photothermal stability and high photothermal conversion efficiency $(52.62 \%)$ in the NIR-II region. In U14 tumor-bearing mice, Pt-Ce6 completely suppressed tumor growth and recurrence under laser irradiation. Thus the nanocomposite shows excellent PDT/photothermal therapy (PTT) synergistic performance in vitro and in vivo.
\end{abstract}

Keywords: hypoxia, catalase, photodynamic, photothermal therapy, cell apoptosis mechanisms

\section{INTRODUCTION}

Hypoxia is one of the basic hallmarks of most solid tumors owing to insufficient blood flow, irregular cancer cell proliferation and inadequate endogenous oxygen, which will resist the therapeutic outcomes of the oxygen- dependent therapy modes including photodynamic therapy (PDT) and radiotherapy (RT), sonodynamic therapy (SDT), and immunotherapy [1-5]. In particular, PDT acting as a non-invasive, specific and controllable treatment has been extensively studied [6-12]. However, the strong dependence of PDT on molecular oxygen severely handicaps its effective application in low-oxygen environment $[13,14]$. So far, various strategies have been developed to overcome tumor hypoxia, which can generally be divided into three categories. (i) Using $\mathrm{O}_{2}$-carrying molecules. Perfluorocarbon, fluorocarbon-chain and perfluoropentane have high affinity to $\mathrm{O}_{2}$ and can dissolve large amount of $\mathrm{O}_{2}$ and directly deliver $\mathrm{O}_{2}$ into tumor to boost the oxygenation degree [15-19]. (ii) Using $\mathrm{O}_{2}$-generating nanomaterials such as $\mathrm{CaO}_{2}$ via chemical decomposition reaction [20,21]. (iii) Using natural catalase (CAT) or CAT-like nanomaterials such as $\mathrm{MnO}_{2}$, $\mathrm{C}_{3} \mathrm{~N}_{4}$, metal-organic frameworks (MOFs) and noble metal nanoparticles [22-27]. Compared with the former two, the third one mainly utilize the tumor microenvironment (TME) to catalyze endogenous $\mathrm{H}_{2} \mathrm{O}_{2}$ to in situ generate $\mathrm{O}_{2}$, which consumes the undesirable tumor metabolites $\left(\mathrm{H}_{2} \mathrm{O}_{2}\right)$ without causing side effects. However, $\mathrm{CaO}_{2}$ with unstable nature cannot perform function steadily and continuously. The inherent shortcomings of natural enzymes including easy inactivation, high cost and difficult modification, greatly limit their practical application. $\mathrm{C}_{3} \mathrm{~N}_{4}$ and other nanozymes require more controllable synthetic design to improve their dispersibility and biocompatibility [28]. Moreover, the types of nanozymes

\footnotetext{
${ }^{1}$ Department of Life and Chemistry, Zhejiang Normal University, Jinhua 321004, China

${ }^{2}$ Institute of Frontier and Interdisciplinarity Science and Institute of Molecular Sciences and Engineering, Shandong University, Qingdao 266237, China

${ }^{3}$ Department of Radiology, the Second Hospital of Jilin University, Changchun 130041, China

† These authors contributed equally to this work.

* Corresponding authors (emails: zgkin@zjnu.edu.cn (Jin Z); cxli@sdu.edu.cn (Li C))
} 
used in this field are relatively unitary. Consequently, it is necessary to develop new nanozymes with CAT-mimicking activity in the application of $\mathrm{O}_{2}$-related tumor therapy in hypoxic tumors.

In recent years, noble metal nanozymes, which combine the advantages of natural enzymes and nanomaterials, have attracted wide attention [29,30]. They exhibit high stability under harsh conditions, low cost, controllable synthesis, adjustable catalytic activity and good biocompatibility, etc. [31,32]. These advantages endow noble metal nanozymes with extensive applications in biomedical fields. On one hand, noble metal nanozymes can mimic the CAT activity to in situ generate $\mathrm{O}_{2}$ to amplify tumor oxygenation, such as Pda-Pt@PCN-FA [28], Pt@UiO-66-NH $\mathrm{NH}_{2} @ A u$ shell [33], P@Pt@P-Au-FA [34] and H-Pd NSs [35]. On the other hand, they have strong near-infrared (NIR) absorption and can be served as photothermal agents (PTAs) to convert light to hyperthermia for photothermal therapy (PTT) [33,36-42]. NIR light exhibits higher tissue transparency and penetration depth as well as weaker autofluorescence relative to visible or ultraviolet (Vis/UV) light [43-46]. More delightfully, gold-silica nanoshells have been used as PTT agent for prostate cancer in clinical trials, in which $94 \%$ $(15 / 16)$ of patients who received treatment showed no signs of cancer after one year [47]. In addition, NIR-II light (1000-1350 nm) has less tissue scattering and absorption, lower background signal and higher maximum permissible exposure (MPE) than NIR-I light $(650-950 \mathrm{~nm})$ [48]. The MPE for skin exposure is $1.0 \mathrm{~W} \mathrm{~cm}^{-2}$ at NIR-II, which is much higher than $0.33 \mathrm{~W} \mathrm{~cm}^{-2}$ at $808 \mathrm{~nm}[44,49-52]$. In light of this, noble metal nanomaterials that have both CAT and NIR-II region photoabsorption activity can provide new chance for the delicate design of nanotheranostic platforms.

Herein, we presented a novel Pt-Ce6 nanocomposite as nanozyme and PTAs at NIR-II $(1064 \mathrm{~nm})$ for PDT/PTT tumor therapy in an orchestrated manner. For details, firstly, Pt nanoparticles (NPs) can act as nanocarriers to link covalently photosensitizer chlorin e6 (Ce6) by polymer $\mathrm{NH}_{2}$-PEG-HS. The modification with PEG can help to ameliorate the stability and biocompatibility of the nanocarrier under physiological conditions, accompanied by prolonging the circulation time in blood and facilitating selective accumulation at the targets through the enhanced permeation and retention (EPR) effect [53]. Due to the high X-ray absorption coefficient, Pt-Ce6 shows considerable computed tomography (CT) imaging. Secondly, Pt-Ce6 can act as a CAT mimicking nanozyme to rapidly catalyze the disintegration of $\mathrm{H}_{2} \mathrm{O}_{2}$ to $\mathrm{O}_{2}$, which can surmount the problem of tumor hypoxia and facilitate the PDT process. Finally, Pt-Ce6 has strong NIR-II light absorption capacity to transform light energy into thermal energy with high photothermal conversion capability $(52.62 \%)$, which further accelerates the decomposition of $\mathrm{H}_{2} \mathrm{O}_{2}$ and enhances the PDT effect. Thus by this reasonable design, synergistic PDT and PTT therapy is expected to achieve the optimal therapeutic effect as compared with single PDT or PTT. More importantly, the apoptosis mechanism of Pt-Ce6-mediated PDT was investigated in detail.

\section{EXPERIMENTAL SECTION}

\section{Materials and general methods}

All chemicals were purchased from commercial suppliers and directly used. Potassium tetrachloroplatinate (II) $\left(\mathrm{K}_{2} \mathrm{PtCl}_{4}\right)$, ascorbic acid, hexadecyltrimethylammoniumbromide (CTAB), ammonium chloride $\left(\mathrm{NH}_{4} \mathrm{Cl}\right), \mathrm{Ce}, 1-$ ethyl-3-[3-(dimethylamino)propyl] carbodiimide hydrochloride (EDC), $N$-hydroxysuccinimide (NHS), methylthiazolyldiphenyl-tetrazolium bromide (MTT), 1,3diphenylisobenzofuran (DPBF), calcein-AM, propidium iodide (PI) and 2,7-dichlorofuorescin diacetate (DCFHDA) were obtained from Aladdin Chemical Reagent. Absolute ethanol $\left(\mathrm{C}_{2} \mathrm{H}_{5} \mathrm{OH}\right)$, dimethyl sulfoxide (DMSO) and hydrogen peroxide $\left(\mathrm{H}_{2} \mathrm{O}_{2}\right)$ solution were bought from Aladdin. $\mathrm{NH}_{2}-\mathrm{PEG}_{3000}-\mathrm{SH}$ was obtained from PegBio Co., Ltd (China). The following antibodies were used in Western blot and immunofluorescence staining: Bax, Bcl-2, Hsp90, Cyt-c, HIF-1 $a$ and COX-IV (Proteintech), cleaved Caspase-3 (Sigma), as well as GAPDH (Goodhere Biotech).

A JEM-1400 transmission electron microscope was used to characterize the morphology of the nanoparticles. The size distribution and zeta potential were recorded by dynamic light scattering analysis (DLS, nano-zs90, Malvern). UV-Vis absorption spectra were tested on a $\mathrm{Hi}$ tachi Dual Beam spectrophotometer (UH5300). X-ray diffraction (XRD) patterns were obtained on a Rigaku D/ max-2550 diffractometer. Fluorescence imaging photographs were taken by a fluorescence inverted microscope (OLYMPUS IX73). An infrared thermal imager (FLIR T630sc) was used to collect temperature changes and thermal image information.

\section{Fabrication of Pt-Ce6 nanocomposite}

Fabrication of $\mathrm{NH}_{2}-\mathrm{PEG}-\mathrm{SH}$ modified porous $\mathrm{Pt}$ nanoparticles (Pt-PEG NPs)

Porous Pt NPs modified with $\mathrm{NH}_{2}$-PEG-SH (Pt-PEG 
NPs) were prepared as previously reported [4]. $\mathrm{A} \mathrm{K}_{2} \mathrm{PtCl}_{4}$ aqueous solution $(0.0249 \mathrm{~g}, 6 \mathrm{~mL})$ was mixed with a CTAB solution $(0.5467 \mathrm{~g}, 15 \mathrm{~mL})$ and heated at $70^{\circ} \mathrm{C}$. Ascorbic acid $(0.0317 \mathrm{~g}, 9.0 \mathrm{~mL})$ was then introduced to the mixture and further heated at $70^{\circ} \mathrm{C}$ for $4 \mathrm{~h}$. Excess $\mathrm{CTAB}$ was removed by washing three times with absolute ethanol, and the solid product was collected by centrifugation (10000 $\left.\mathrm{r} \mathrm{min}^{-1}, 5 \mathrm{~min}\right)$. Next, the nanoparticles were dispersed in absolute ethanol. Before conjugation with $\mathrm{NH}_{2}$-PEG-SH, CTAB was removed by heating at $60^{\circ} \mathrm{C}$ for $2 \mathrm{~h}$ in ammonium nitrate ethanol solution $\left(2 \mathrm{mg} \mathrm{mL}^{-1}\right)$. Then $10 \mathrm{mg}$ of $\mathrm{NH}_{2}$-PEG-SH was added and stirred overnight. The products were collected and washed with deionized water for three times to remove the free $\mathrm{NH}_{2}$-PEG-SH. The as-obtained sample was stored at $4^{\circ} \mathrm{C}$ for further usage.

\section{Preparation of Pt-Ce6 nanocomposite}

EDC ( $8 \mathrm{mg})$ and NHS (12 mg) were introduced to DMSO including $1 \mathrm{mg}$ of Ce6 to form a mixed solution, which was stirred for $1 \mathrm{~h}$ and subsequently added to the Pt-PEG nanoparticles prepared in the previous step. The solid product was collected after being stirred for $12 \mathrm{~h}$ and washed three times with deionized water. Finally, the as-synthesized Pt-Ce6 was dispersed in deionized water for use.

\section{Photothermal properties of Pt-Ce6 nanocomposite}

An aliquot $(0.2 \mathrm{~mL})$ of water dispersion of Pt-Ce6 NPs $\left(100 \mu \mathrm{g} \mathrm{mL}^{-1}\right)$ was irradiated with 1064 or $808 \mathrm{~nm}$ lasers with varied power densities of $0.25,0.5$ and $0.75 \mathrm{~W} \mathrm{~cm}^{-2}$, and different concentrations of $\mathrm{Pt}-\mathrm{Ce} 6$ dispersions (0, $6.25,12.5,25,50,100$ and $200 \mu \mathrm{g} \mathrm{mL}^{-1}$ ) were irradiated with $0.5 \mathrm{~W} \mathrm{~cm}^{-2}$ lasers at 1064 or $808 \mathrm{~nm}$. The corresponding temperatures and thermal images are recorded every $30 \mathrm{~s}$ with an infrared camera.

\section{Extracellular and intracellular oxygen detection}

For in vitro detection of oxygen production, $\mathrm{Pt}-\mathrm{Ce} 6$ was dispersed in $5 \mathrm{~mL}$ of phosphate buffered saline (PBS, pH 5.0, 6.0, and 7.0) containing $\mathrm{H}_{2} \mathrm{O}_{2}$ with different concentrations $\left(0,0.0625,0.125,0.25,0.5\right.$ and $\left.1 \mathrm{mmol} \mathrm{L}^{-1}\right)$, and the final level of Pt-Ce6 was $25 \mu \mathrm{g} \mathrm{mL}^{-1}$. A JPB-607A portable dissolved oxygen meter was used to test the concentration change of dissolved oxygen in the solution within $20 \mathrm{~min}$. In order to evaluate the continuous catalytic oxygen production capacity of $\mathrm{Pt}-\mathrm{Ce} 6$, when the oxygen concentration in the solution increased to a steady state, Pt-Ce6 was isolated by centrifugation $\left(13,000 \mathrm{r} \mathrm{min}^{-1}, 10 \mathrm{~min}\right)$ and re-distributed in $5 \mathrm{~mL}$ of PBS containing $1 \mathrm{mmol} \mathrm{L}^{-1}$ of $\mathrm{H}_{2} \mathrm{O}_{2}$, and the oxygen content in the solution was recorded for $20 \mathrm{~min}$.

Intracellular $\mathrm{O}_{2}$ production was measured using $\left[\mathrm{Ru}(\mathrm{DPP})_{3}\right] \mathrm{Cl}_{2}$ (RDPP) as an oxygen probe [54]. HeLa cells were seeded into a 24 -well culture plate (with a density of $0.2 \times 10^{5}$ cells per well) and incubated for another $24 \mathrm{~h}$ in a transparent box full of nitrogen. After being washed three times with PBS, the cells were cultured in Dulbecco's modified Eagle's medium (DMEM) containing $100 \mu \mathrm{mol} \mathrm{L}^{-1} \mathrm{H}_{2} \mathrm{O}_{2}$ at $37^{\circ} \mathrm{C}$ for $45 \mathrm{~min}$. Then cells only with Pt-Ce6 were treated as described above, with untreated cells serving as controls. Finally, the cells were washed three times with PBS and the corresponding fluorescence images were examined under an inverted fluorescence microscope.

\section{Extracellular ${ }^{1} \mathrm{O}_{2}$ and intracellular ROS detection}

Extracellular ${ }^{1} \mathrm{O}_{2}$ was measured using DPBF. In a typical procedure, $30 \mu \mathrm{L}$ of DPBF solution $\left(1 \mathrm{mg} \mathrm{mL}^{-1}\right.$, dissolved in absolute ethanol) was added to $2 \mathrm{~mL}$ of $\mathrm{Pt}-\mathrm{Ce} 6$ dispersion. The UV-Vis absorption spectra of DPBF were measured after $650 \mathrm{~nm}$ laser irradiation $\left(0.15 \mathrm{~W} \mathrm{~cm}^{-2}\right.$, $5 \mathrm{~min}$ ). DCFH-DA was used to measure intracellular reactive oxygen species (ROS) levels. HeLa cells were incubated with Pt-Ce6 or free Ce6 for $4 \mathrm{~h}$, rinsed with PBS to remove the noninternalized nanomaterials, and then fresh serum-free medium containing DCFH-DA $\left(10 \mu \mathrm{mol} \mathrm{L}^{-1}\right)$ was added to the cells, followed by incubation in the dark for another $30 \mathrm{~min}$. The HeLa cells were then irradiated with a $650-\mathrm{nm}$ laser at a power density of $0.15 \mathrm{~W} \mathrm{~cm}^{-2}$ for $5 \mathrm{~min}$. Finally, the fluorescence images were observed with an inverted fluorescence microscope. For cells pretreated with ROS scavenger $\mathrm{N}$ acetyl- $L$-cysteine (NAC), the cells were first pre-treated with $10 \mathrm{mmol} \mathrm{L}^{-1} \mathrm{NAC}$ and then incubated with Pt-Ce6 for $4 \mathrm{~h}$. After being washed three times with PBS to remove extracellular nanomaterials, the cells were incubated with DCFH-DA for $30 \mathrm{~min}$, and then irradiated with $650 \mathrm{~nm}$ laser. The fluorescence signal was detected with an inverted microscope.

\section{Cellular uptake and cytotoxicity assay}

HeLa cells were cultured in a 12-well plate for $24 \mathrm{~h}$, then the medium was removed, and $100 \mu \mathrm{g} \mathrm{mL}^{-1}$ of Pt-Ce6 dispersion or free Ce6 was added. After $4 \mathrm{~h}$, the cells were washed three times with PBS to remove the unabsorbed Pt-Ce6 or photosensitizers. The cells were then digested by trypsin, collected and resuspended in PBS, which was further treated with $35-\mathrm{mm}$ nylon mesh so as to form a single cell suspension. Finally, flow cytometry and inverted fluorescence microscopy were used to detect the 
fluorescent signal and analyze the cellular uptake of the material.

MTT assay was utilized to measure the cytotoxicity of Pt-Ce6 or free Ce6. First, L929 and HeLa cells were inoculated into a 96-well culture plate (5000 cells per well). After overnight incubation, the cells were treated with PtCe6 at $0,20,40,80$, and $160 \mu \mathrm{g} \mathrm{mL}^{-1}$ or the same amount of free Ce 6 in the dark at $37^{\circ} \mathrm{C}$ for $4 \mathrm{~h}$. After that, $10 \mu \mathrm{L}$ of MTT $\left(5 \mathrm{mg} \mathrm{mL}^{-1}\right)$ was added into each well and incubated for another $4 \mathrm{~h}$. Finally, $100 \mu \mathrm{L}$ of lysis buffer $(0.14 \% \mathrm{HCl}$ and $4 \%$ Triton X-100 in 2-propanol) was used to lyse the cells. A multifunctional microplate reader was used to measure the absorbance at $595 \mathrm{~nm}$ to analyze the cell survival rate.

\section{In vitro $\mathrm{PDT}, \mathrm{PTT}$ and their combined effects}

For PDT effects under normoxic conditions, HeLa cells were seeded in 96-well plates and incubated for $24 \mathrm{~h}$ at $37^{\circ} \mathrm{C}, 5 \% \mathrm{CO}_{2}$. Various concentrations of Pt-Ce6 or free Ce6 were added and cultured for $4 \mathrm{~h}$. After being washed three times with PBS to remove extracellular nanomaterials, the cells were irradiated for $5 \mathrm{~min}(650 \mathrm{~nm}$, $0.15 \mathrm{~W} \mathrm{~cm}^{-2}$ ) in air. After addition of fresh culture medium, the cell viability was detected via the above standard MTT assay.

To demonstrate that Pt-Ce6 can catalyze the decomposition of $\mathrm{H}_{2} \mathrm{O}_{2}$ to generate oxygen and enhance the effect of PDT, we also tested the PDT effect of Pt-Ce6 and free Ce6 under hypoxia. Different concentrations of PtCe6 or free Ce6 were incubated with HeLa cells for $4 \mathrm{~h}$, and then placed in a hypoxic incubator. After $1 \mathrm{~h}$, the cells were irradiated for $5 \mathrm{~min}\left(0.15 \mathrm{~W} \mathrm{~cm}^{-2}\right)$ in a $\mathrm{N}_{2}$ atmosphere using a $650-\mathrm{nm}$ laser. The cell viability was then tested by standard MTT assay.

For the combination of PTT and PDT, HeLa cells were first seeded in 96 -well plates and cultured at $37^{\circ} \mathrm{C}$ for $24 \mathrm{~h}$. After incubation with different concentrations of PtCe6 for $4 \mathrm{~h}$, the cells were washed three times with PBS, fresh medium was added. The cells were treated with different conditions: (1) control, (2) 650+1064 nm laser $\left(0.15 \mathrm{~W} \mathrm{~cm}^{-2}, 5 \mathrm{~min}\right.$ and $\left.1 \mathrm{~W} \mathrm{~cm}^{-2}, 10 \mathrm{~min}\right),(3) \mathrm{Pt}-\mathrm{Ce} 6$ $+1064 \mathrm{~nm}$ laser ( $1 \mathrm{~W} \mathrm{~cm}^{-2}, 10 \mathrm{~min}$ ), (4) Pt-Ce6+650 nm laser $\left(0.15 \mathrm{~W} \mathrm{~cm}^{-2}, 5 \mathrm{~min}\right)$ and (5) Pt-Ce6+650+1064 nm laser $\left(0.15 \mathrm{~W} \mathrm{~cm}^{-2}, 5 \mathrm{~min}\right.$ and $\left.1 \mathrm{~W} \mathrm{~cm}^{-2}, 10 \mathrm{~min}\right)$. Next, cell viability was measured using standard MTT assay.

To confirm the killing outcome of the samples on cancer cells, the cells treated with Pt-Ce6 $\left(100 \mu \mathrm{g} \mathrm{mL}^{-1}\right)$ were stained with $1 \mathrm{mmol} \mathrm{L}^{-1}$ of calcein $\mathrm{AM}$ and $5 \mathrm{mmol} \mathrm{L}^{-1}$ of PI, and the stained cells were observed with an inverted fluorescence microscope.

\section{Analysis of MMP}

The mitochondrial membrane potential (MMP, $\Delta \Psi_{\mathrm{m}}$ ) was measured by an MMP assay kit with JC-1 (Meilun). Briefly, HeLa cells were seeded in six-well plates and incubated with Pt-Ce6 for $4 \mathrm{~h}$ at $37^{\circ} \mathrm{C}$. The cells were washed three times with PBS. After fresh medium was added, the cells were irradiated by a $650-\mathrm{nm}$ laser for $5 \mathrm{~min}$ and further incubated for $5 \mathrm{~h}$. JC- 1 staining solution was then introduced, mixed well and incubated for additional $20 \mathrm{~min}$. Finally, the stained cells were cleaned twice with cold JC-1 buffer, refreshed by new medium and observed with an inverted fluorescence microscope.

\section{Western blot}

PDT-treated, PTT-treated or untreated cells were lysed with cold lysis buffer $\left(125 \mathrm{mmol} \mathrm{L}^{-1}\right.$ of $\mathrm{NaCl}$, $20 \mathrm{mmol} \mathrm{L}^{-1}$ of Tris, $\mathrm{pH} \quad 7.5,1 \%$ Nonidet P-40, $1 \mathrm{mmol} \mathrm{L}{ }^{-1}$ of EDTA and protease inhibitor cocktail) to prepare whole cell lysate. Cytoplasmic and mitochondrial protein extraction kit (Sangon Biotech) was used to prepare mitochondria/cytosol fractionation according to the manufacturer's instruction. Protein samples were denatured in sodium dodecyl sulfate (SDS) sample buffer by boiling for $5 \mathrm{~min}$ and separated by SDS-PAGE. Western blot was performed as described previously [55]. ImageJ software was used to quantify the Western blot by densitometric analysis.

\section{Annexin V/PI assay}

Annexin V/PI kit (Sangon Biotech) was utilized to detect apoptosis based on the manufacturer's instruction. Briefly, HeLa cells were seeded in 12-well plates and incubated overnight. Then the cells were treated with PtCe6 or free Ce6 for $4 \mathrm{~h}$. Next, the cells were washed three times with PBS, refreshed with new medium, and exposed to $650 \mathrm{~nm}$ laser irradiation $\left(0.15 \mathrm{~W} \mathrm{~cm}^{-2}, 5 \mathrm{~min}\right)$, followed by another 12-h incubation. Cold PBS was used to harvest the cells, which were washed twice with and resuspended in binding buffer. Aliquots of cells were stained with $5 \mu \mathrm{L}$ of Annexin V-FITC for 15 min followed by $10 \mu \mathrm{L}$ PI staining in the dark for $5 \mathrm{~min}$. Flow cytometry was used to observe the fluorescence intensity of the cells.

\section{Animal model}

Six-week-old female Balb/c mice were bought from the Experimental Animal Center of Jilin University (Changchun). All animal experiments were carried out according to the "China National Animal Protection and Use Regulations". U14 cells were injected subcutaneously into the 
left side of healthy Balb/c mice to establish a U14 tumor model. When the tumor volume reached approximately $100 \mathrm{~mm}^{3}$, in vivo studies were conducted.

\section{Biocompatibility of Pt-Ce6 in vivo}

Healthy female Balb/c mice were categorized into two groups in a random manner, including saline (control group) and Pt-Ce6 nanocomposite group. Aliquots $(100 \mu \mathrm{L})$ of saline or Pt-Ce6 nanocomposites with concentrations of $4 \mathrm{mg} \mathrm{mL}^{-1}$ were intravenously injected into the corresponding groups of mice. Fourteen days after the injection, the mice were sacrificed and their blood was collected for complete blood biochemical assay. Then the main tissues and organs were gathered and stained with hematoxylin and eosin (H\&E).

\section{Tissue distribution}

To assess the tissue distribution, tumor-bearing mice ( $n=$ 3) were injected intravenously with $100 \mu \mathrm{L}$ of Pt-Ce6 nanocomposites $\left(4 \mathrm{mg} \mathrm{mL}^{-1}\right)$ and sacrificed $24 \mathrm{~h}$ later. The main organs of the liver, heart, lung, spleen, kidney and tumor tissues were excised and weighed, and further digested at $70^{\circ} \mathrm{C}$ for three days in aqua regia so as to analyze the concentration of $\mathrm{Pt}$ by using inductively coupled plasma massspectrometry (ICP-MS).

\section{Photothermal and CT imaging}

For photothermal imaging, after intratumoral injection of $\mathrm{Pt}-\mathrm{Ce} 6$, the mice bearing tumors were anesthetized, and then the tumor site was exposed to a 1064-nm laser for $5 \mathrm{~min}\left(1 \mathrm{~W} \mathrm{~cm}^{-2}\right)$. Infrared thermal imager was used to record the temperature changes of the tumor during laser irradiation.

To evaluate CT contrast efficiency in vitro, Pt-Ce6 dispersions with different levels $(0,2,4,6,8,10$ and $12 \mathrm{mg} \mathrm{mL}^{-1}$ ) were placed in centrifuge tubes to obtain CT images. For CT imaging in vivo, Pt-Ce6 $\left(6 \mathrm{mg} \mathrm{mL}^{-1}\right.$, $100 \mu \mathrm{L}$ ) dispersion was injected intratumorally, and then tumor-bearing mice were anesthetized. Both in vitro and in vivo $\mathrm{CT}$ imaging were conducted on a Philips CT imaging apparatus.

\section{In vivo anti-tumor experiment}

The tumor-bearing mice were randomly divided into seven groups $(n=5)$ : (1) control, (2) 650+1064 nm laser, (3) Pt-Ce6, (4) Ce6+650 nm laser, (5) Pt-Ce6+650 nm laser, (6) Pt-Ce6+1064 nm laser and (7) Pt-Ce6 $+650+1064 \mathrm{~nm}$ laser. The exposure dose of 650 and $1064 \mathrm{~nm}$ laser towards the tumor site was $0.15 \mathrm{~W} \mathrm{~cm}^{-2}$ (5 min) and $1 \mathrm{~W} \mathrm{~cm}^{-2}(5 \mathrm{~min})$, respectively. After in- travenous injection of $100 \mu \mathrm{L}\left(4 \mathrm{mg} \mathrm{mL}^{-1}\right)$ Pt-Ce6 or equivalent amount of free Ce6 for $24 \mathrm{~h}$, the mice were treated in accordance with the experimental procedures. The body weight and tumor volume of mice were measured every two days for a total of 14 days. The tumor volume $(V)$ and the relative tumor volume $\left(V_{\mathrm{r}}\right)$ were calculated according to the formula $V=$ length $\times$ width $^{2} / 2$ and $V_{\mathrm{r}}=V / V_{0}\left(V_{0}\right.$ is the corresponding tumor volume at the beginning of treatment), respectively. After the fourteenth days of treatment, the representative mice in different groups were executed. And major organs and tumors were then gathered for histopathological analysis. After sectioning, the cells were further stained with $\mathrm{H} \& \mathrm{E}$ to measure the structure and state of the cells, and the terminal deoxynucleotidyl transferase dUTP nick end label (TUNEL) was used to analyze DNA fragments during apoptosis.

\section{Immunofluorescence staining}

The collected tumors of mice were fixed in $10 \%$ paraformaldehyde, embedded in paraffin, cut into about 4 microns, treated with Triton X-100 (0.5\%) for $10 \mathrm{~min}$ and incubated with BSA for $30 \mathrm{~min}$. Then the sections were incubated overnight with 1:200 of HIF- $1 \alpha$ antibody at $4^{\circ} \mathrm{C}$. Subsequently, the corresponding secondary antibody (1:500) was introduced at $37^{\circ} \mathrm{C}$ for $1 \mathrm{~h}$. After excess antibodies were removed by rinsing the cover glass with PBS, images were observed with a confocal microscope.

\section{RESULTS AND DISCUSSION}

\section{Fabrication and characterization of Pt-Ce6 nanocomposites}

The preparation process for the Pt-Ce6 nanocomposite is shown in Scheme 1. Porous Pt NPs were synthesized according to a previous report with some modifications [4]. In brief, $\mathrm{K}_{2} \mathrm{PtCl}_{4}$ was reduced at $70^{\circ} \mathrm{C}$ with $\mathrm{CTAB}$ as stabilizer and ascorbic acid as reductant. After the reaction, the Pt NPs was washed and refluxed in ammonium nitrate ethanol solution at $60^{\circ} \mathrm{C}$ for $2 \mathrm{~h}$ to completely remove unreacted CTAB. From the TEM image (Fig. 1a), the as-prepared Pt NPs exhibit spherical and porous morphology with a diameter of approximately $71.5 \mathrm{~nm}$ (Fig. S1a). As shown in Fig. 1b, the XRD pattern of the porous Pt NPs is highly consistent with that of bulk Pt (JCPDS 04-0802). In order to improve the biocompatibility of nanoparticles, the surface of Pt NPs was modified by $\mathrm{NH}_{2}$-PEG-SH and linked covalently with the photosensitizers Ce6. The mercapto group at one end of 

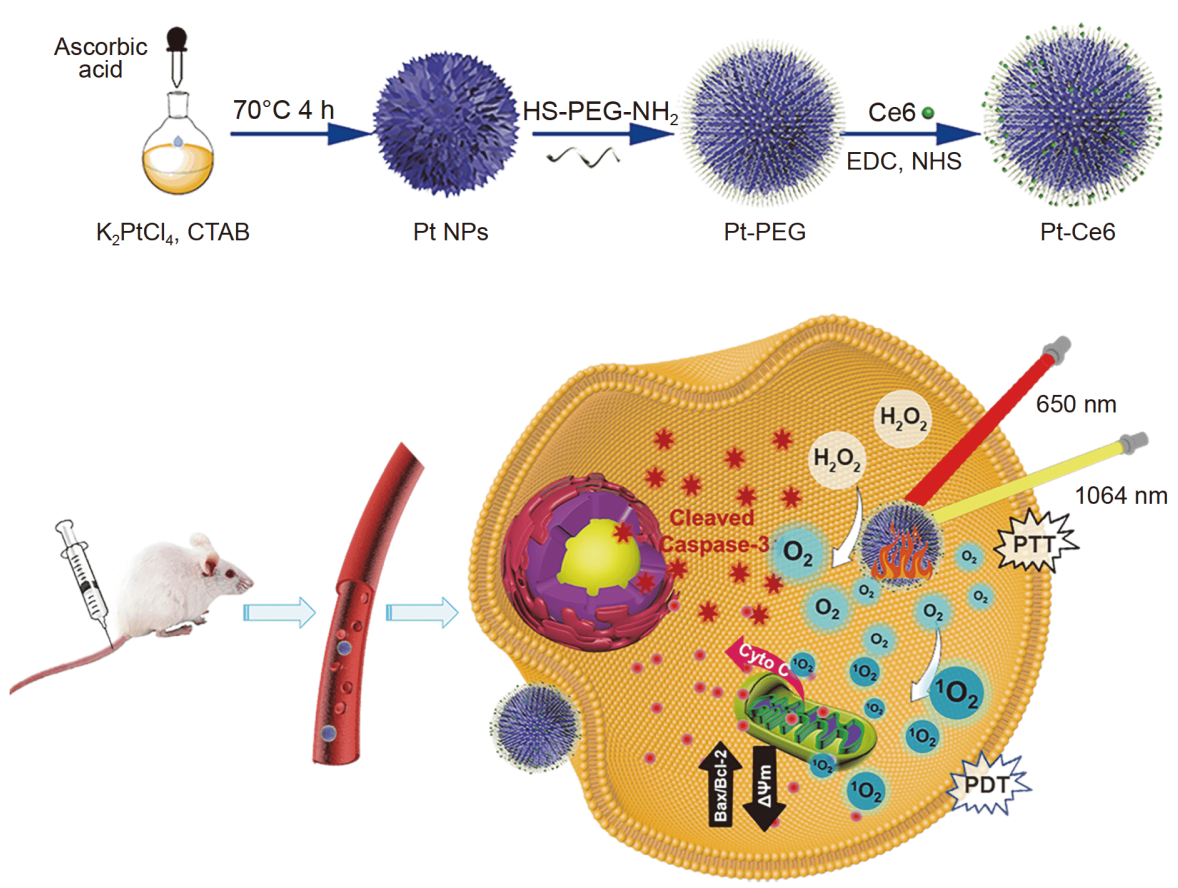

Scheme 1 A schematic graph showing the preparation process of Pt-Ce6 and their application in PDT/PTT synergistic therapy.

$\mathrm{NH}_{2}$-PEG-SH could be strongly bound to Pt NPs, and amino on the other end can be connected to Ce6 by forming an amide base. The successful linking of Ce6 can be confirmed by the change of the UV-Vis absorption spectra and the zeta potentials. As shown in Fig. 1c, PtCe6 has characteristic absorption peaks similar to free Ce6 at about 400 and $660 \mathrm{~nm}$. The loading of Ce6 on Pt NPs was calculated to be about $5 \mathrm{wt} \%$ based on the standard curve of Ce6 (Fig. S1b). At the same time, the synthesized Pt NPs have strong surface plasmon resonance absorption in the NIR-I and NIR-II. The zeta potentials of Pt NPs, Pt-PEG, and Pt-Ce6 in water are $-6.26,5.05$, and $-11.2 \mathrm{mV}$, respectively (Fig. 1d). As shown in Fig. 1e, based on the $\mathrm{N}_{2}$ adsorption isotherm, the nitrogen adsorption curve of Pt NPs at $77 \mathrm{~K}$ is a typical IV-type adsorption curve, indicating that the compound has a mesoporous structure with mean pore size of $3.7 \mathrm{~nm}$. Additionally, the obtained Pt-Ce6 nanocomposite can be well dispersed in water, PBS and cell culture medium without obvious aggregation, indicating the good stability of nanomaterials under physiological conditions (Fig. 1f).

\section{Catalytic activity and ROS production of Pt-Ce6 nanocomposite}

To demonstrate that Pt-Ce6 has high CAT-mimicking activity, the catalytic ability of Pt-Ce6 at different $\mathrm{pH}$ (5.0,
6.0 and 7.0) was tested (for the potential mechanism of oxygen production, see Fig. S2 in Supplementary information). As expected, a large amount of bubbles were rapidly generated after the addition of Pt-Ce6 to $\mathrm{H}_{2} \mathrm{O}_{2}$ solutions with different $\mathrm{pH}$ values while no bubbles were observed without Pt-Ce6 (Fig. S3). In addition, a portable dissolved oxygen meter was used to measure the content of dissolved oxygen in the solution, as shown in Fig. 2a-c. After adding $\mathrm{H}_{2} \mathrm{O}_{2}$ to the solution containing Pt-Ce6 under different $\mathrm{pH}$ conditions, the content of dissolved oxygen increased significantly. Due to anaerobic glycolysis, the TME is frequently featured with an acidic extracellular $\mathrm{pH}$ within the range of 6.2-6.9, mildly lower than 7.2-7.4 for normal tissues [56]. Thus, Pt-Ce6 exhibited desirable CAT activity within the $\mathrm{pH}$ range of TME. In order to assess the ability of Pt-Ce6 to continuously catalyze oxygen production, exogenous $\mathrm{H}_{2} \mathrm{O}_{2}\left(1 \mathrm{mmol} \mathrm{L}{ }^{-1}\right)$ was continuously added to the system every $20 \mathrm{~min}$. The results showed that Pt-Ce6 continuously catalyzed oxygen production in three cycles with good stability (Fig. 2d-f). Simultaneously, the photothermal effect of Pt-Ce6 under NIR light can accelerate the decomposition of $\mathrm{H}_{2} \mathrm{O}_{2}$. As shown in Fig. S4a, the decomposition rate of $\mathrm{H}_{2} \mathrm{O}_{2}$ at $40^{\circ} \mathrm{C}$ is much faster than that at $20^{\circ} \mathrm{C}$. The excellent catalytic activity and photothermal transition ability of Pt-Ce6 make it possible to enhance PDT effect of hypoxic tumors. 

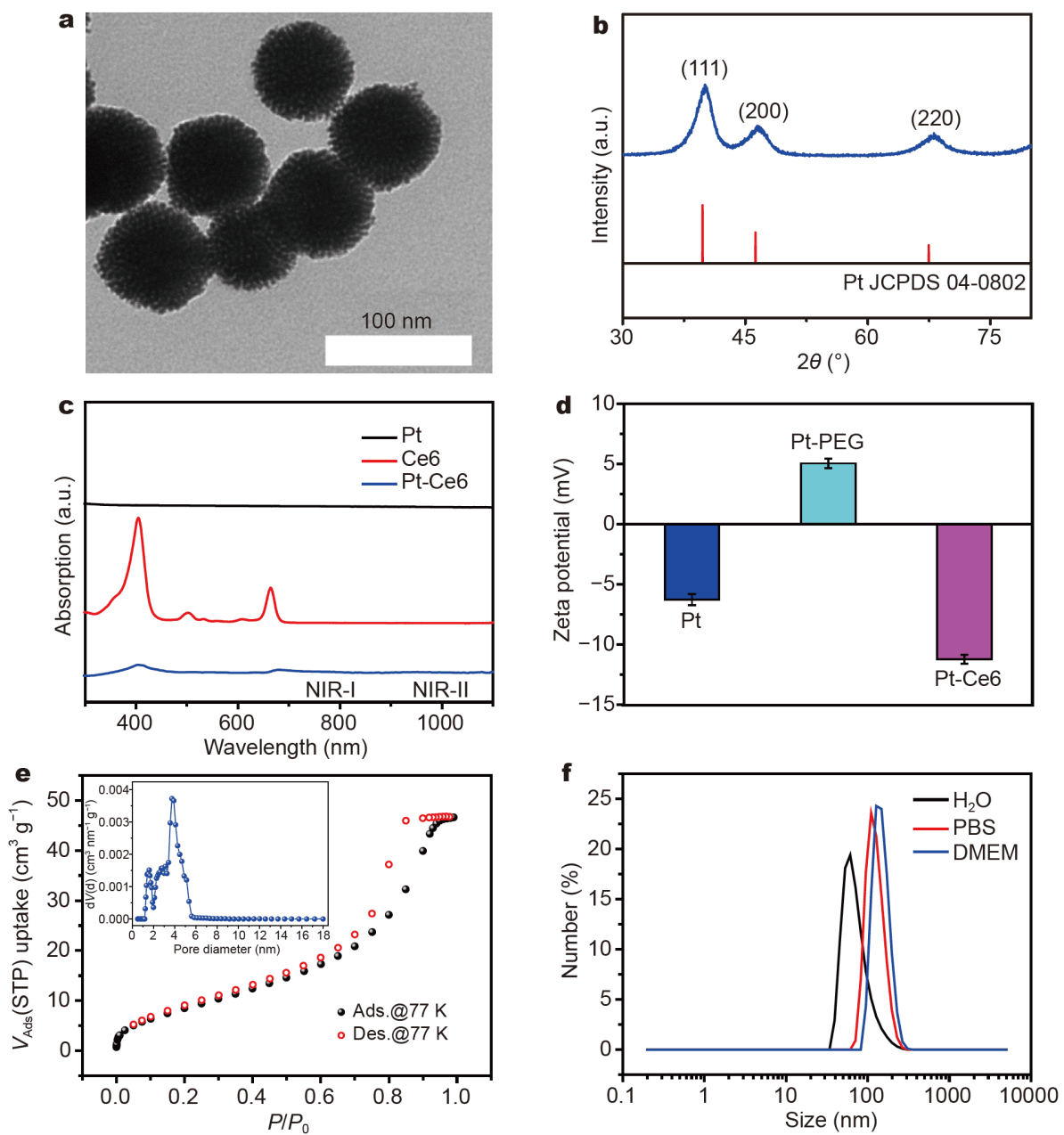

Figure 1 TEM image (a), XRD pattern (b), nitrogen adsorption isotherm and pore size distribution (e) of Pt NPs. UV-Vis absorption spectra (c) and zeta potentials (d) of Pt NPs, Ce6 and Pt-Ce6 nanocomposites. (f) DLS measured sizes of Pt-Ce6 in different solutions, including water (black line), PBS (red line) and cell culture medium (blue line).

Encouraged by the excellent catalytic performance of Pt-Ce6, we have also studied its ability to catalyze the decomposition of $\mathrm{H}_{2} \mathrm{O}_{2}$ to $\mathrm{O}_{2}$ in HeLa cells. RDPP was chosen as fluorescent probe to evaluate the intracellular $\mathrm{O}_{2}$ concentration because it can react irreversibly with $\mathrm{O}_{2}$ and its fluorescence was then quenched [54]. The cells untreated or treated with $\mathrm{H}_{2} \mathrm{O}_{2}$ only showed bright green fluorescence while those treated with Pt-Ce6 exhibited weak green fluorescence (Fig. 2g). More strikingly, no green fluorescence appeared in the cells treated with PtCe6 and $\mathrm{H}_{2} \mathrm{O}_{2}$, which suggested that internalized Pt-Ce6 can effectively catalyze the decomposition of intracellular $\mathrm{H}_{2} \mathrm{O}_{2}$ to produce $\mathrm{O}_{2}$, which can alleviate the hypoxia of tumor cells. This further validates the good catalytic properties of Pt-Ce6 and its potential for enhancing PDT during tumor treatment.
ROS with strong cytotoxicity causes irreversible destruction to crucial organelles and DNA, eventually resulting in apoptosis and necrosis [57]. Therefore, the efficiency of photosensitive agents in producing ROS under light excitation is the key to PDT. First, the ability of Pt-Ce6 and free Ce6 to generate ${ }^{1} \mathrm{O}_{2}$ was measured in vitro using $\mathrm{DPBF}$ as an ROS probe, which can interact with ${ }^{1} \mathrm{O}_{2}$ to induce the decrease of its absorption peaks at about $420 \mathrm{~nm}$ [55]. As can be seen, the absorption value of DPBF at $420 \mathrm{~nm}$ has no obvious variation when only $650 \mathrm{~nm}$ laser exposure is used (Fig. S4b). After the addition of Pt-Ce6 or free Ce6, the absorption peaks of DPBF at $420 \mathrm{~nm}$ reduced gradually with the time of $650 \mathrm{~nm}$ irradiation (Fig. 3a-c). Both of them can efficiently produce ${ }^{1} \mathrm{O}_{2}$, and their ${ }^{1} \mathrm{O}_{2}$ production capacity is almost comparable with the same content of photo- 

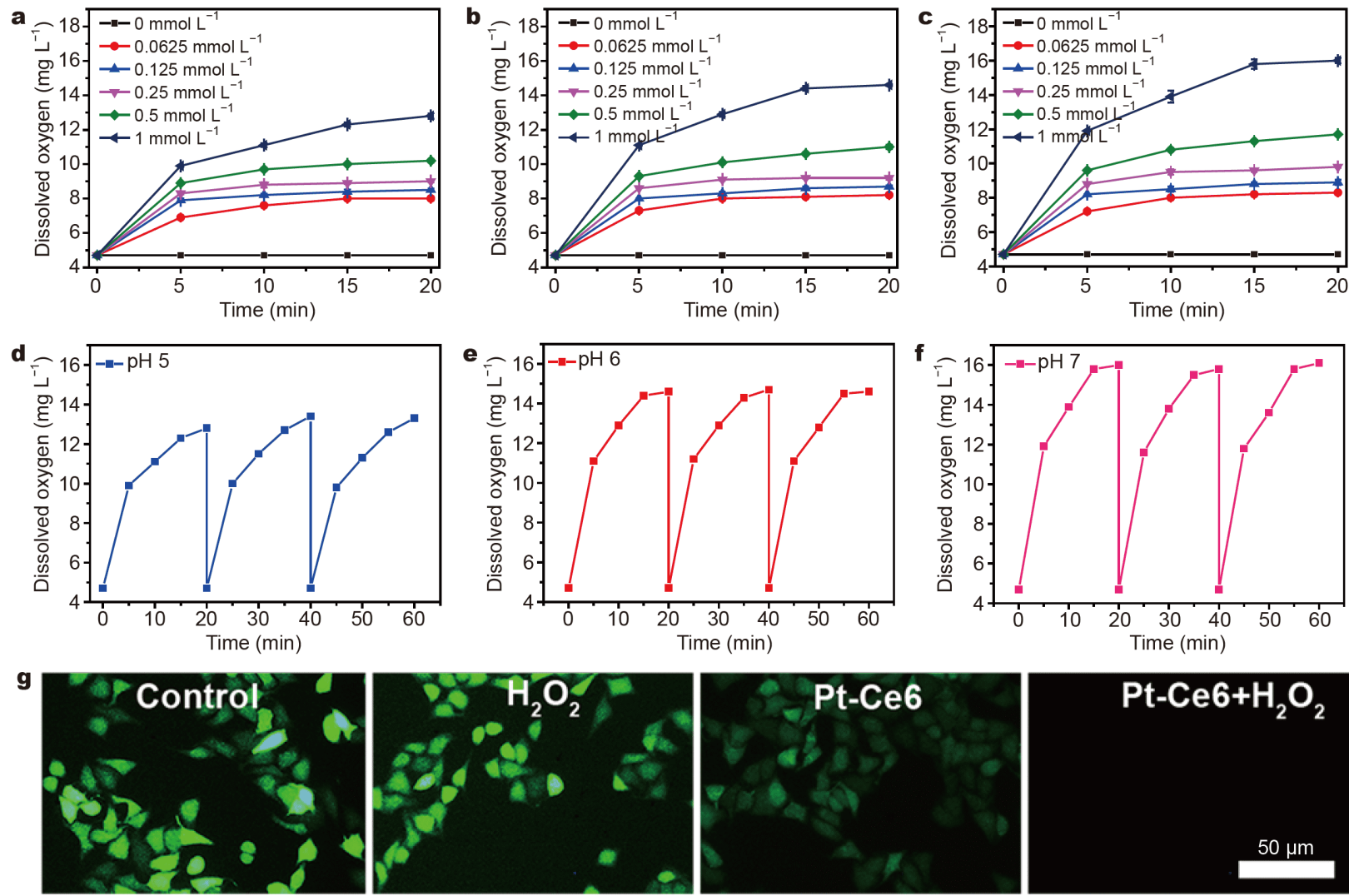

Figure $2 \mathrm{O}_{2}$ concentration of $\mathrm{H}_{2} \mathrm{O}_{2}$ solution after addition of Pt-Ce6 or $\mathrm{H}_{2} \mathrm{O}$ under different $\mathrm{pH}$ conditions: (a) pH 5, (b) pH 6 and (c) pH 7. (d-f) Concentration of dissolved oxygen in a solution containing Pt-Ce6 after repeated addition of $\mathrm{H}_{2} \mathrm{O}_{2}$ under different $\mathrm{pH}$ conditions. (g) Fluorescent microscopy images of intracellular $\mathrm{O}_{2}$ in HeLa cells subjected to different treatments and detected with $\mathrm{O}_{2}$ probe RDPP.

sensitizers. After that, the effect of the presence of $\mathrm{H}_{2} \mathrm{O}_{2}$ on the rate of ${ }^{1} \mathrm{O}_{2}$ produced by Pt-Ce6 and free $\mathrm{Ce} 6$ was investigated. After adding $\mathrm{H}_{2} \mathrm{O}_{2}$, the efficiency of ${ }^{1} \mathrm{O}_{2}$ produced by Pt-Ce6 was obviously improved, but it had no significant effect on the efficiency of ${ }^{1} \mathrm{O}_{2}$ produced by free Ce6 (Fig. 3d-f). This shows that Pt-Ce6 can catalyze $\mathrm{H}_{2} \mathrm{O}_{2}$ decomposition to generate $\mathrm{O}_{2}$ and increase the concentration of $\mathrm{O}_{2}$. By contrast, $\mathrm{Ce} 6$ cannot catalyze the decomposition of $\mathrm{H}_{2} \mathrm{O}_{2}$, so the presence of $\mathrm{H}_{2} \mathrm{O}_{2}$ has no effect on the ${ }^{1} \mathrm{O}_{2}$ production.

In addition, DCFH-DA as ROS probe was used to detect the intracellular ROS production. DCFH-DA can be hydrolyzed into DCFH by intracellular esterase [55]. Once in the cell, DCFH-DA will be hydrolyzed by cellular lactase to form DCFH, which can be further oxidized by intracellular ROS to produce fluorescent DCF. Under normoxic conditions, the bright green fluorescence was seen in HeLa cells treated with Pt-Ce6 or Ce6 after the 650-nm light irradiation (Fig. 3g). In comparison, none or weak green fluorescence was observed in cells treated with Pt-Ce6, Ce6, irradiated alone or pretreated with ROS scavenger NAC. Under hypoxic conditions, bright fluorescence was observed in Pt-Ce6 treated cells, while only weak green fluorescence was observed in free Ce6 treated cells (Fig. $3 \mathrm{~h}$ ). The results show that under hypoxic conditions, Pt-Ce6 maintained the ability to produce ${ }^{1} \mathrm{O}_{2}$ under $650 \mathrm{~nm}$ light irradiation, demonstrating a potential application in PDT for hypoxic tumors.

\section{Photothermal performance of Pt-Ce6 nanocomposite}

Next, we studied the optical absorption and photothermal properties of Pt-Ce6, including absorbance, photothermal conversion efficiency and photostability, which are three basic parameters to evaluate the photothermal performances of a kind of PTAs. The optical properties of the Pt-Ce6 aqueous dispersion show a broad and strong absorption band ranging from visible to NIR region, including the NIR-I and NIR-II biological windows, showing the potential of photothermal conversion with the irradiation of $808 \mathrm{~nm}$ (NIR-I) or $1064 \mathrm{~nm}$ (NIR-II) 

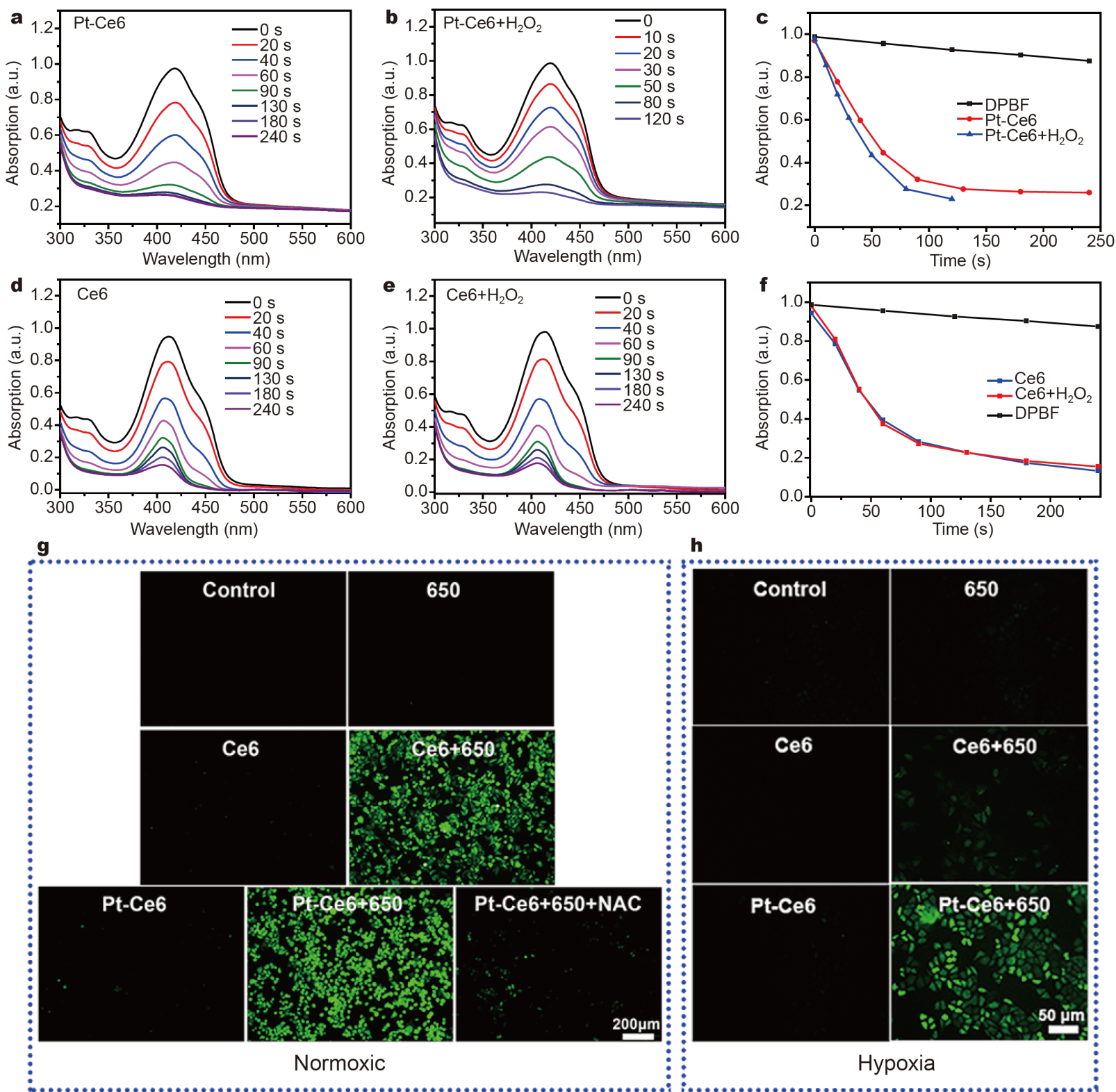

h

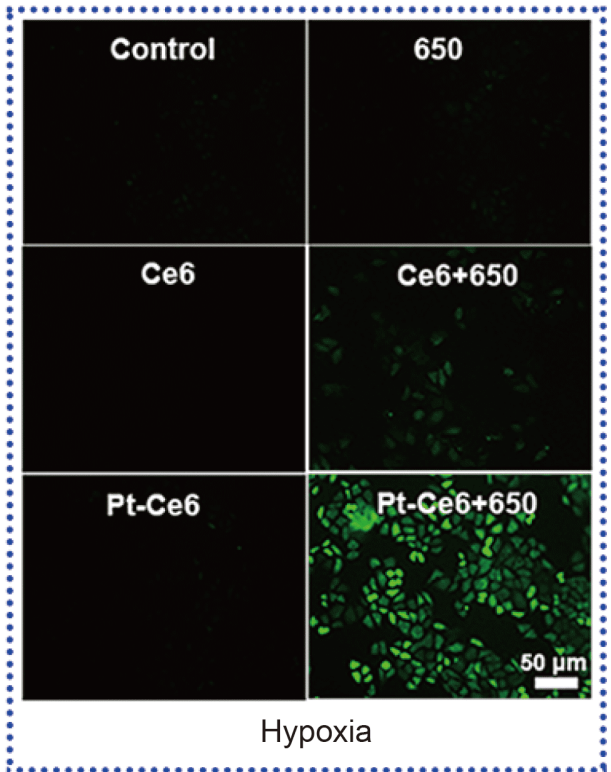

Figure 3 (a, b) Absorption spectrum changes of DPBF under $650 \mathrm{~nm}$ laser irradiation with Pt-Ce6 in the absence or presence of $\mathrm{H}_{2} \mathrm{O}_{2}$. $(\mathrm{d}, \mathrm{e})$ Absorption spectrum changes of DPBF under $650 \mathrm{~nm}$ laser irradiation with free Ce6 in the absence or presence of $\mathrm{H}_{2} \mathrm{O}_{2}$. Decay curves of DPBF absorption at $420 \mathrm{~nm}$ in Pt-Ce6 (c) or free Ce6 (f) dispersions with or without $\mathrm{H}_{2} \mathrm{O}_{2}$ after different durations of irradiation $\left(650 \mathrm{~nm}, 0.15 \mathrm{~W} \mathrm{~cm}^{-2}\right)$. Intracellular ROS levels were evaluated in HeLa cells stained with ROS probe DCFH-DA under normoxic (g) and hypoxic (h) conditions.

(Fig. 1c). According to Lambert-Beer's law, the extinction coefficient $(\varepsilon)$ is 7.33 and $7.24 \mathrm{~L} \mathrm{~g}^{-1} \mathrm{~cm}^{-1}$ at 808 and $1064 \mathrm{~nm}$, respectively (Fig. S5a-c), indicating that Pt-Ce6 NPs have powerful NIR light harvesting performance. Subsequently, the Pt-Ce6 NPs of different concentrations were exposed to 808 or $1064 \mathrm{~nm}$ laser $\left(0.5 \mathrm{~W} \mathrm{~cm}^{-2}\right)$ to assess their photothermal conversion efficiency. The temperature elevation of the solution exhibited a con- centration-dependent pattern (Fig. 4a, d and g). After PtCe6 $\left(100 \mu \mathrm{g} \mathrm{mL}^{-1}\right)$ was laser-irradiated at 808 or $1064 \mathrm{~nm}$ for $300 \mathrm{~s}$, the maximum temperature changes $\left(\Delta T_{\max }\right)$ reached 40 or $45.1^{\circ} \mathrm{C}$, respectively.

In contrast, the pure water had negligible temperature variation. In addition, the photothermal effects of Pt-Ce6 under different powers of 808 or $1064 \mathrm{~nm}$ laser were studied. $\Delta T_{\max }$ of the Pt-Ce6 aqueous dispersion showed a 

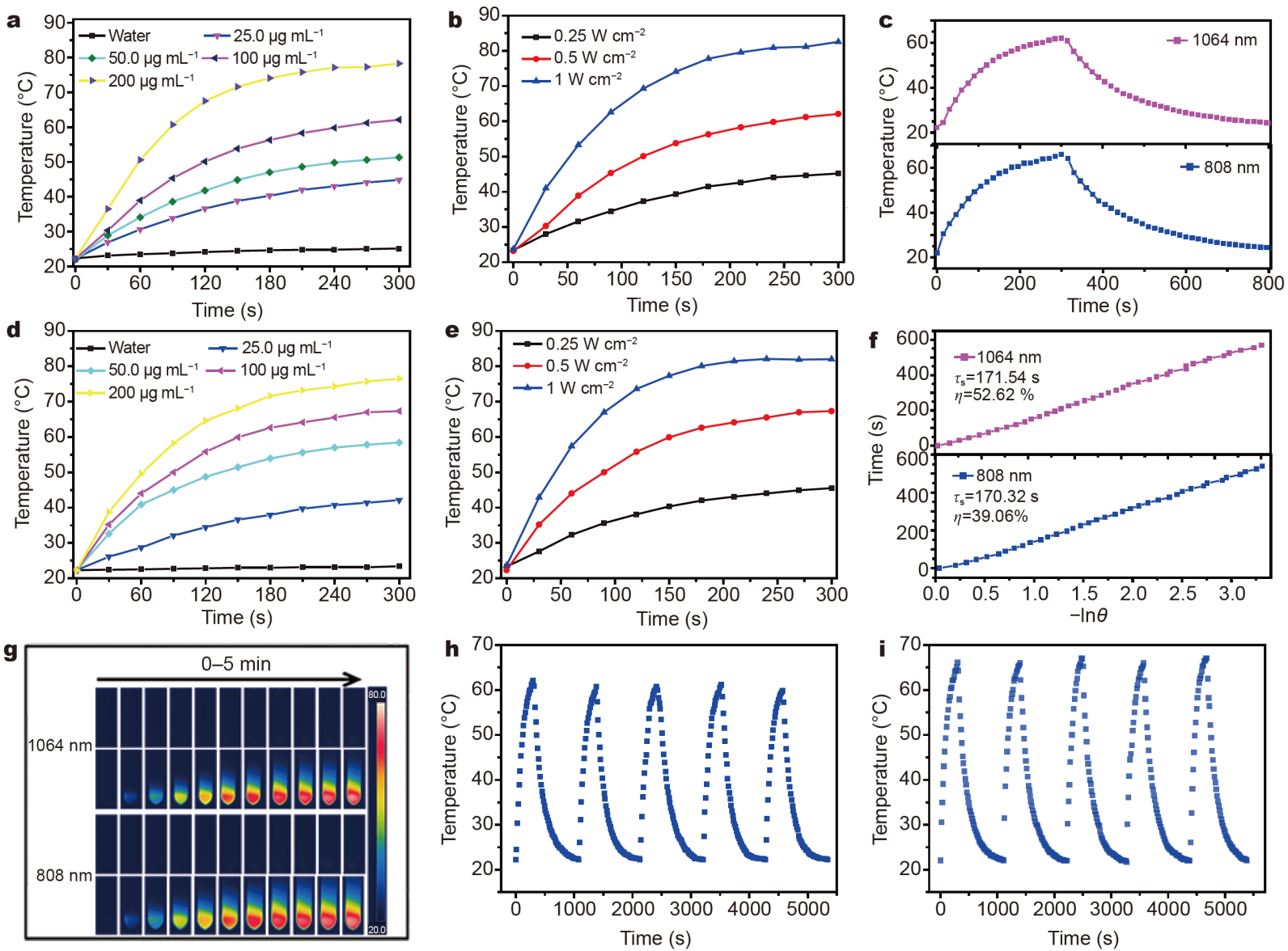

Figure 4 Photothermal-heating curves of Pt-Ce6 dispersions at varied concentrations $\left(0,12.5,25,50,100\right.$ and $\left.200 \mu \mathrm{g} \mathrm{mL}^{-1}\right) \mathrm{with}^{\mathrm{irradiation}}$ of $808(\mathrm{a})$ or $1064 \mathrm{~nm}(\mathrm{~d})$ laser $\left(0.5 \mathrm{~W} \mathrm{~cm}^{-2}\right)$ for $300 \mathrm{~s}$. Temperature profiles of Pt-Ce6 dispersions at $100 \mu \mathrm{g} \mathrm{mL} \mathrm{m}^{-1} \mathrm{under} 1064$ (b) or $808 \mathrm{~nm}$ (e) light irradiation at different power densities $\left(0.25,0.5\right.$ and $1.0 \mathrm{~W} \mathrm{~cm}^{-2}$ ) for $300 \mathrm{~s}$. (c) Photothermal heating and cooling curves. (f) The heat transfer time constant calculated from the cooling time. (g) Infrared thermography of aqueous dispersion without (upper) or with $200 \mu \mathrm{g} \mathrm{mL} \mathrm{m}^{-1}$ of Pt-Ce6 (lower) under NIR light irradiation. The heating curve of the Pt-Ce6 dispersion in deionized water at 5 laser on/off cycles $\left(0.5 \mathrm{~W} \mathrm{~cm}^{-2}\right)$ under $1064(\mathrm{~h}) \mathrm{or}^{2} 808 \mathrm{~nm}(\mathrm{i})$ laser irradiation.

power-dependent photothermal effect (Fig. 4b and e). The photothermal conversion efficiency of Pt-Ce6 was $39.06 \%$ at $808 \mathrm{~nm}$ and $52.62 \%$ at $1064 \mathrm{~nm}$, respectively (Fig. $4 \mathrm{c}$ and $\mathrm{f}$ ), much higher than those of typical $\mathrm{SnTe} @ \mathrm{MnO}_{2}$-SP nanosheets (43.9\%) [45], Au nanorods (21\%) [58], $\mathrm{Cu}_{9} \mathrm{~S}_{5}$ nanocrystals (25.7\%) [59], Prussian Blue (41.4\%) [60] and $\mathrm{Nb}_{2} \mathrm{C}$ (46.65\%) [61]. Furthermore, the photothermal stability of Pt-Ce6 NPs was evaluated by recording five recycling temperature changes when their dispersions were irradiated with $1064 \mathrm{~nm}$ laser for $500 \mathrm{~s}$ (laser on) and subsequently cooled naturally (laser off) (Fig. 4h and i). There was no significant variation of the photothermal properties of Pt-Ce6 NPs during the cyclic process, indicating that Pt-Ce6 NPs have good photothermal stability and potential as a long-lasting photothermal conversion agent for PTT.

\section{In vitro PDT effects of Pt-Ce6 nanocomposite}

Before the in vivo anti-tumor experiments, we evaluated the cytotoxicity and cellular uptake of free Ce6 and PtCe6. The toxicity of Pt-Ce6 and free Ce6 to HeLa and L929 ells was studied by typical MTT assay (Fig. 5a and Fig. S6). When the concentration was as high as $160 \mu \mathrm{g} \mathrm{mL}{ }^{-1}$, the cell survival rate was more than $80 \%$, showing no obvious cytotoxicity of Pt-Ce6 and free Ce6 to both cells. Then cellular uptake of free $\mathrm{Ce} 6$ and Pt-Ce6 in HeLa cells was analyzed by flow cytometry and inverted fluorescence microscope. Ce6 shows bright red fluorescence and can be used to monitor the degree of cell uptake of nanomaterials.

Through flow cytometry analysis, it was found that with the increase of incubation time, the efficiency of Pt-Ce6 uptake by the cells gradually increased (Fig. S7). In ad- 

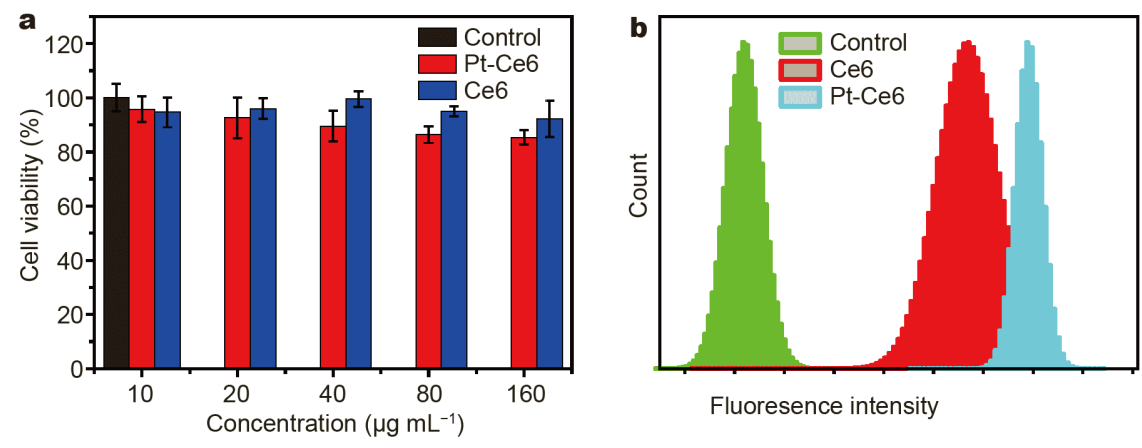

Fluoresence intensity

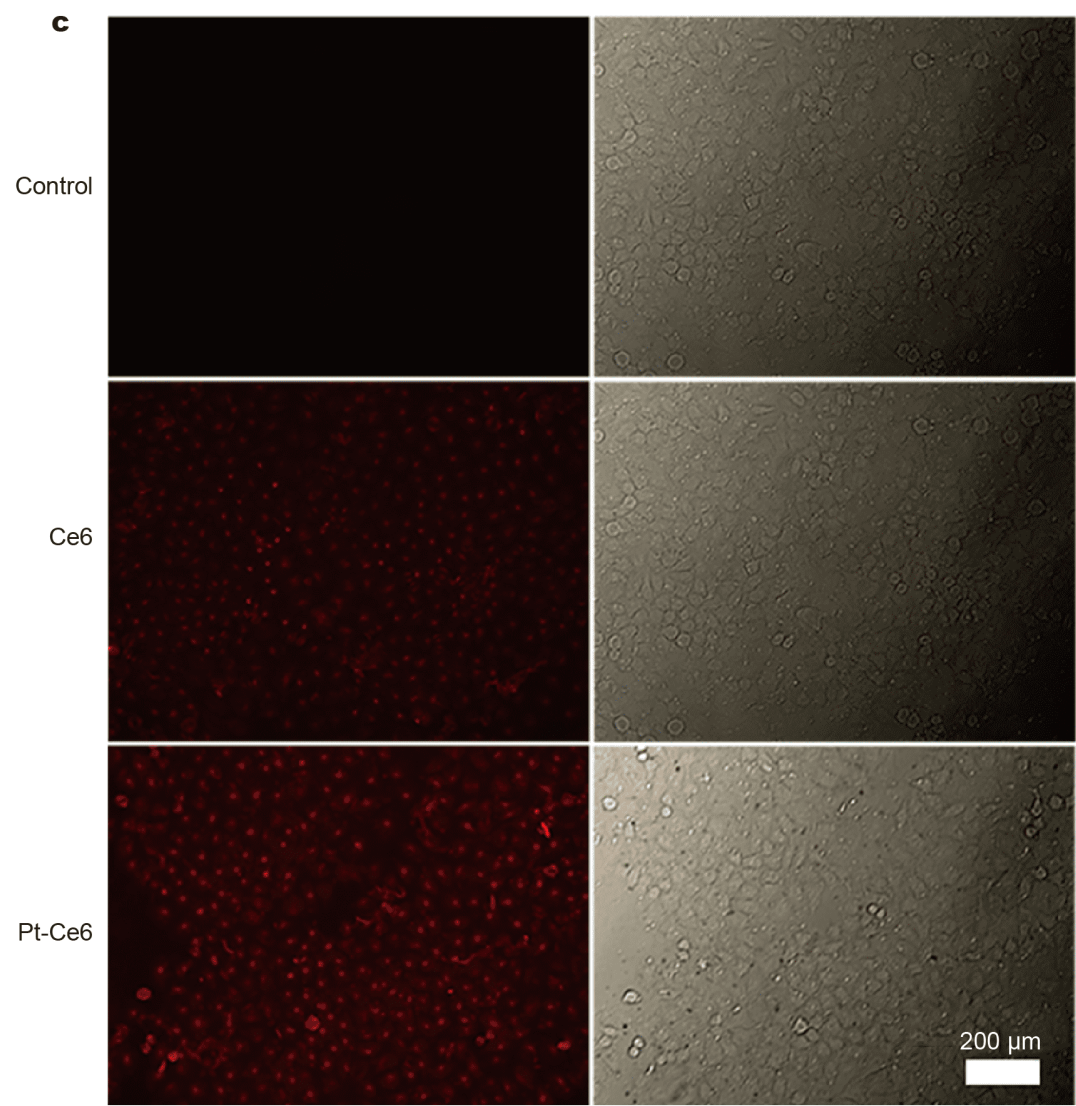

Figure 5 Cytotoxicity and cellular uptake of Pt-Ce6 in HeLa cells. (a) Viability analysis of HeLa cells incubated with various levels of Pt-Ce6 or free Ce6. Flow cytometry analysis (b), red fluorescence and bright field images (c) of HeLa cells untreated or treated with $100 \mu \mathrm{gg} \mathrm{mL}^{-1} \mathrm{Pt}-\mathrm{Ce} 6 \mathrm{or}$ free Ce6 for $4 \mathrm{~h}$.

dition, at the same incubation time, HeLa cells treated with Pt-Ce6 showed a stronger fluorescence signal relative to the control or free Ce6 groups (Fig. 5b). Meanwhile, fluorescent microscopy images also showed brighter red fluorescence in HeLa cells incubated with PtCe6 than that of Ce6 (Fig. 5c). These results illustrated that the Pt-Ce6 can be internalized more effectively by HeLa cells. And Ce6 photosensitizers exhibit better stability by covalently attaching to the surface of Pt NPs, effectively avoiding self-aggregation and fluorescence quenching.

Uncontrolled growth of cancer cells can eventually lead to a lack of oxygen in the tumor, which is detrimental to oxygen-based PDT. Tumor tissues will accumulate a large amount of $\mathrm{H}_{2} \mathrm{O}_{2}$, which promotes tumor heterogeneity, neovascularization, invasion and metastasis $[62,63]$. Here, we expect that $\mathrm{Pt}-\mathrm{Ce} 6$ can catalyze the decomposition of overproduced $\mathrm{H}_{2} \mathrm{O}_{2}$ in tumor tissues to enrich oxygen to reinforce the PDT effect, and simultaneously consume $\mathrm{H}_{2} \mathrm{O}_{2}$ to suppress tumor invasion and metastasis. To 
prove this, we first explored the killing ability of various concentrations of free Ce6 or Pt-Ce6 to HeLa cells after $650 \mathrm{~nm}$ laser irradiation in normoxic and hypoxic atmospheres. Under normoxic conditions, both Pt-Ce6 and Ce6 showed strong killing effects on HeLa cells after laser irradiation (Fig. 6a). It is worth noting that compared with the same concentration of free Ce6, Pt-Ce6 showed more pronounced cell killing ability, which may be due to a larger amount of Pt-Ce6 being internalized by the cells. Under hypoxic conditions, Pt-Ce6 remained similar cell killing ability. In contrast, the cell killing ability of free Ce6 was much weaker under hypoxic conditions than that of normoxic conditions (Fig. 6b). We also stained cells with PI and calcein AM to determine PDT effects by distinguishing dead (red only) and live (green only) cells (Fig. 6c, d), which were consistent with above cell viability data. Both results demonstrated that the PDT effect of free Ce6 was compromised by low oxygen conditions, probably due to that free $\mathrm{Ce} 6$ failed to catalyze the conversion of $\mathrm{H}_{2} \mathrm{O}_{2}$ to ${ }^{1} \mathrm{O}_{2}$ (Fig. 3a-f). Comparatively, the excellent catalytic performance of Pt-Ce6 plays an important role in low oxygen conditions, which can catalyze the decomposition of large amounts of $\mathrm{H}_{2} \mathrm{O}_{2}$ to $\mathrm{O}_{2}$. Therefore, Pt-Ce6 retains potent PDT effect even when oxygen supply is inadequate in the TME.

\section{Cell apoptosis mechanisms for Pt-Ce6-mediated PDT}

PDT could induce cell death through apoptosis, necrosis and autophagy pathways [64]. We employed Caspase-3 staining assay and Annexin V/PI staining assay to verify whether Pt-Ce6-mediated PDT could induce apoptosis. As the major executioner Caspase, Caspase- 3 is activated by proteolytic cleavage of its inactive pro-Caspase-3 during most cases of apoptosis. Therefore, cleaved Caspase- 3 could be used as a marker of apoptosis [55]. Utilizing immunofluorescence staining against cleaved Caspase-3, we found that there are massive apoptotic cells after HeLa cells were treated with Pt-Ce6 and irradiated at $650 \mathrm{~nm}$, while few apoptotic cells were observed in HeLa cells treated with Pt-Ce6 or irradiated alone (Fig. 7a). We also performed flow cytometry with Annexin V/PI staining, another assay commonly used for quantification of apoptosis and necrosis. As shown in Fig. $7 \mathrm{~b}$ and c, laser irradiation at $650 \mathrm{~nm}$ had little effect on early apoptotic cell population in untreated cells $(3.42 \% v$ s. $3.84 \%)$. In contrast, irradiation caused an obvious increase of early apoptotic cell population in Ce6-treated cells $(15.02 \% v s$. $27.52 \%)$ and Pt-Ce6-treated cells $(11.10 \%$ vs. $34.46 \%)$. Thus, we concluded that Pt-Ce6-mediated PDT could induce apoptosis of cancer cells. It is worth noting that Pt-Ce6 treated cells undergo more apoptosis after laser
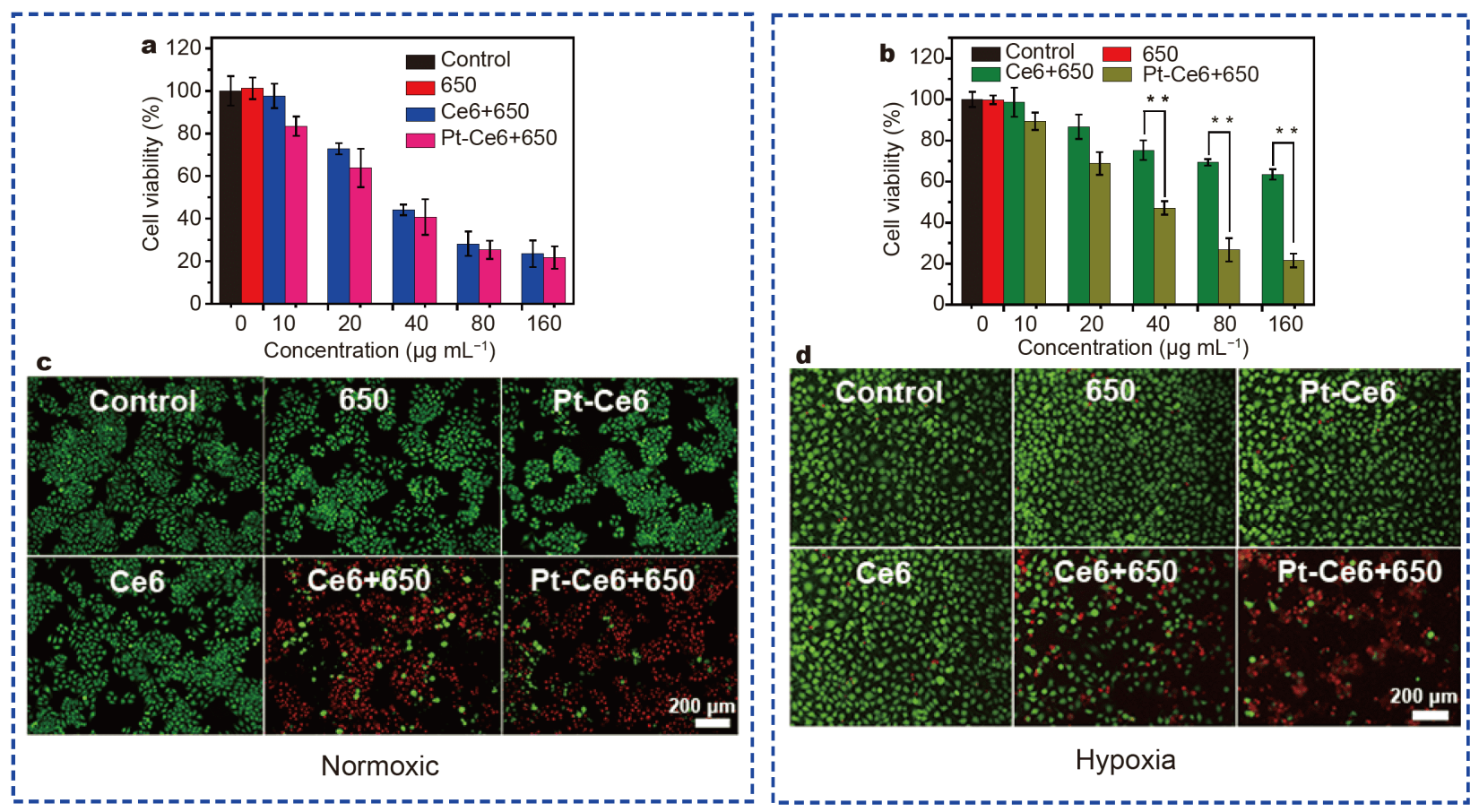

Figure 6 Cell death in HeLa cells induced by Pt-Ce6-mediated PDT. Cell viabilities (a, b) and the corresponding microscopy images (c, d) of HeLa cells stained with calcein AM/PI after different treatments. Note that $(\mathrm{a}, \mathrm{c})$ for normoxic conditions and $(\mathrm{b}, \mathrm{d})$ for hypoxia conditions. The $p$ values in (b) were calculated by Tukey's posttest $\left({ }^{* *} p<0.01\right)$. 

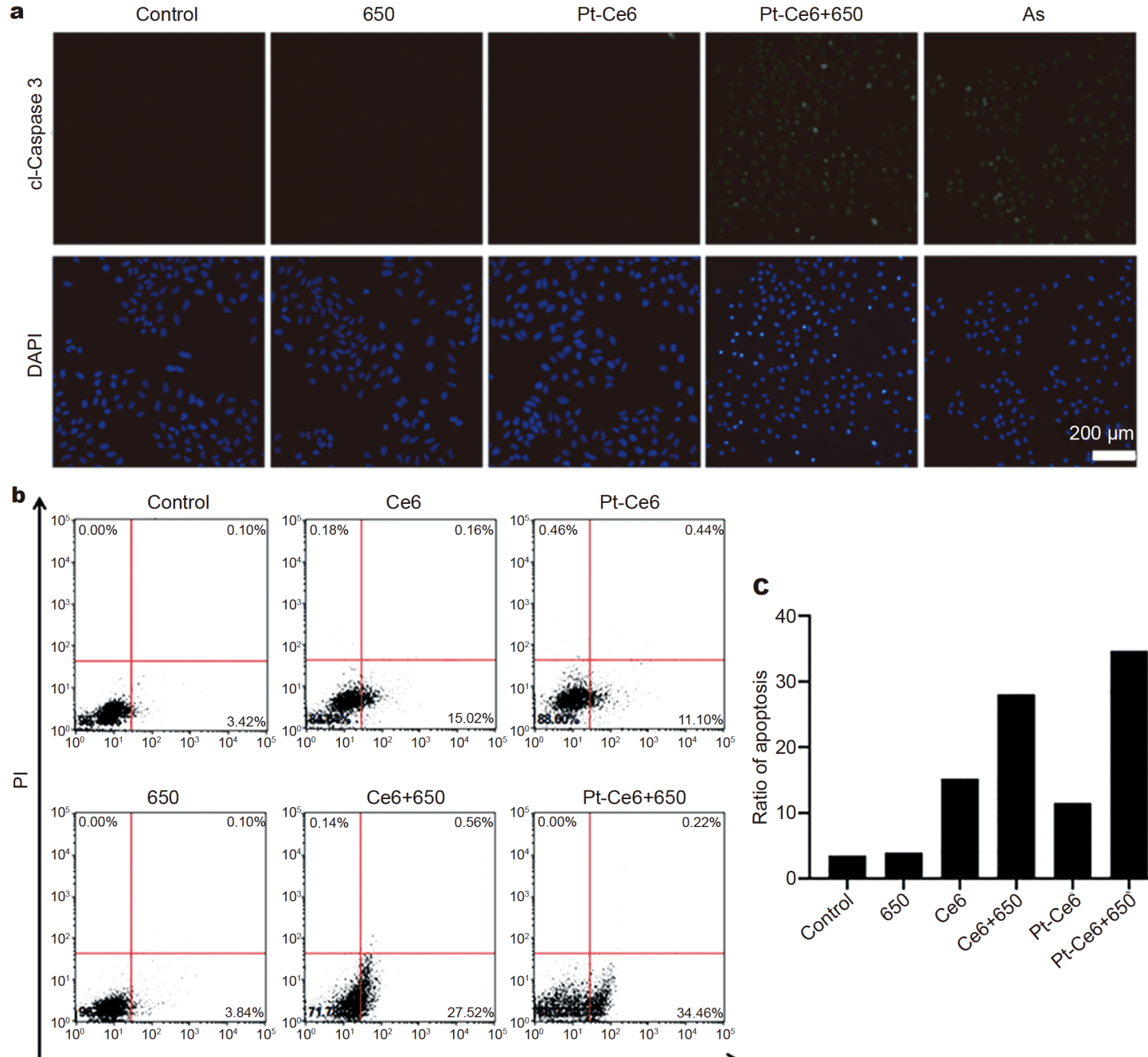

C
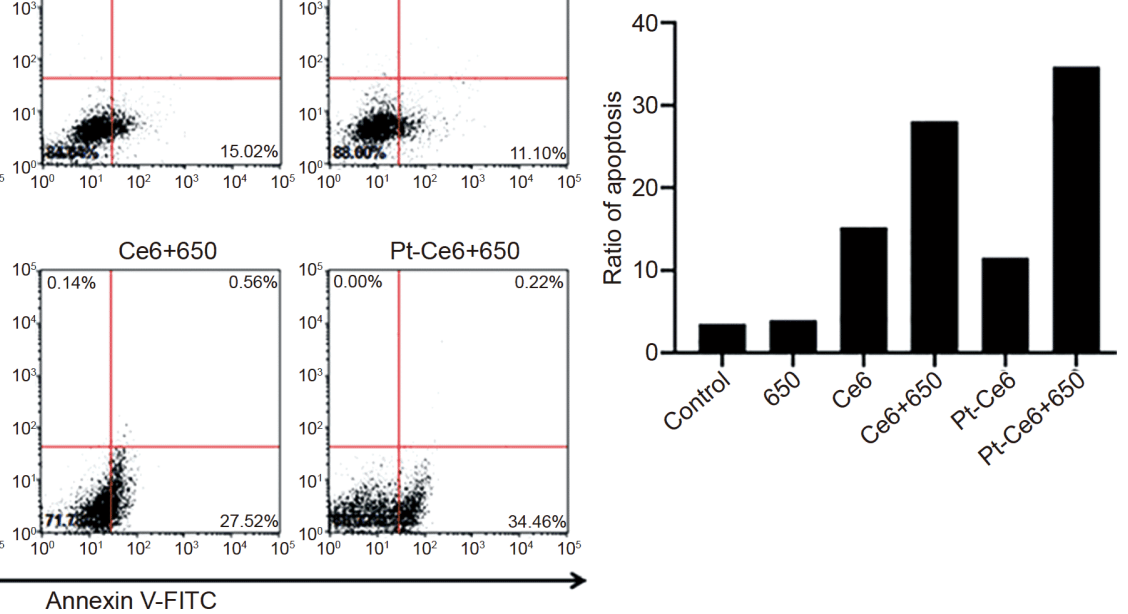

Figure 7 Apoptosis of HeLa cells induced by Pt-Ce6-mediated PDT. (a, b) HeLa cells were treated with Pt-Ce6 for 4 h, followed by laser irradiation. After incubation for $3 \mathrm{~h}$, apoptotic levels were determined by cleaved Caspase-3 staining (a) and Annexin V/PI staining (b). HeLa cells treated with sodium arsenite for $5 \mathrm{~h}$ were served as positive control in (a). (c) Quantitative analysis of apoptotic levels shown in (b).

irradiation, which may be due to more efficient cell uptake of Pt-Ce6 than Ce6.

Apoptosis can be induced by two major pathways: the mitochondria-mediated pathway (intrinsic) and the death receptor-mediated pathway (extrinsic) [2]. In order to determine whether Pt-Ce6-mediated PDT induced apoptosis of cancer cells via mitochondria-mediated pathway, we utilized three different approaches to investigate characteristics of mitochondrial damage: elevated Bax/Bcl-2 ratio, Cyt-c leakage and decreased $\Delta \Psi_{\mathrm{m}}$ $[65,66]$. Firstly, the expression level of Bcl-2 family proteins that are the key regulators of apoptosis via governing mitochondrial outer membrane permeabilization, was measured by Western blot. After the treatment of Pt-
Ce6 and irradiation at $650 \mathrm{~nm}$, the expression of proapoptotic Bax protein up-regulated while that of antiapoptotic Bcl-2 protein down-regulated, resulting in an elevated $\mathrm{Bax} / \mathrm{Bcl}-2$ ratio (Fig. 8a and b). Secondly, we found that Pt-Ce6 treatment followed by laser irradiation led to augmented Cyt-c concentration in the cytosol, concomitant with declined Cyt-c level in the mitochondria, indicating Cyt-c can be released from the mitochondria to the cytosol (Fig. 8c and d). Finally, we used the JC-1 staining assay to detect integrity of MMP. In normal mitochondria, JC-1 aggregates are abundant in the mitochondrial matrix and emit red fluorescence. In unhealthy mitochondria, JC-1 can only exist in the cytosol as a monomer, producing green fluorescence [57]. 
a

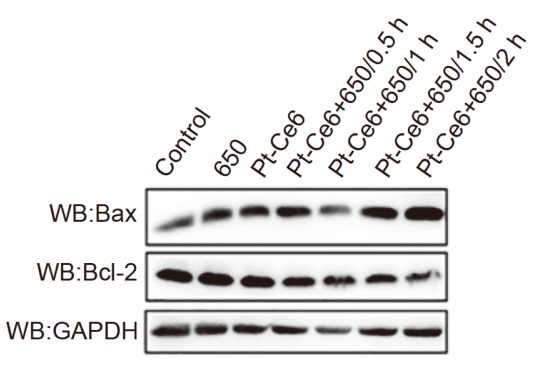

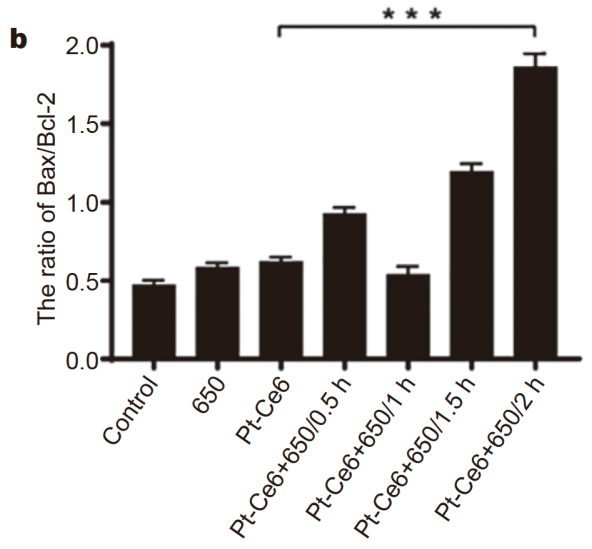

Cytosol
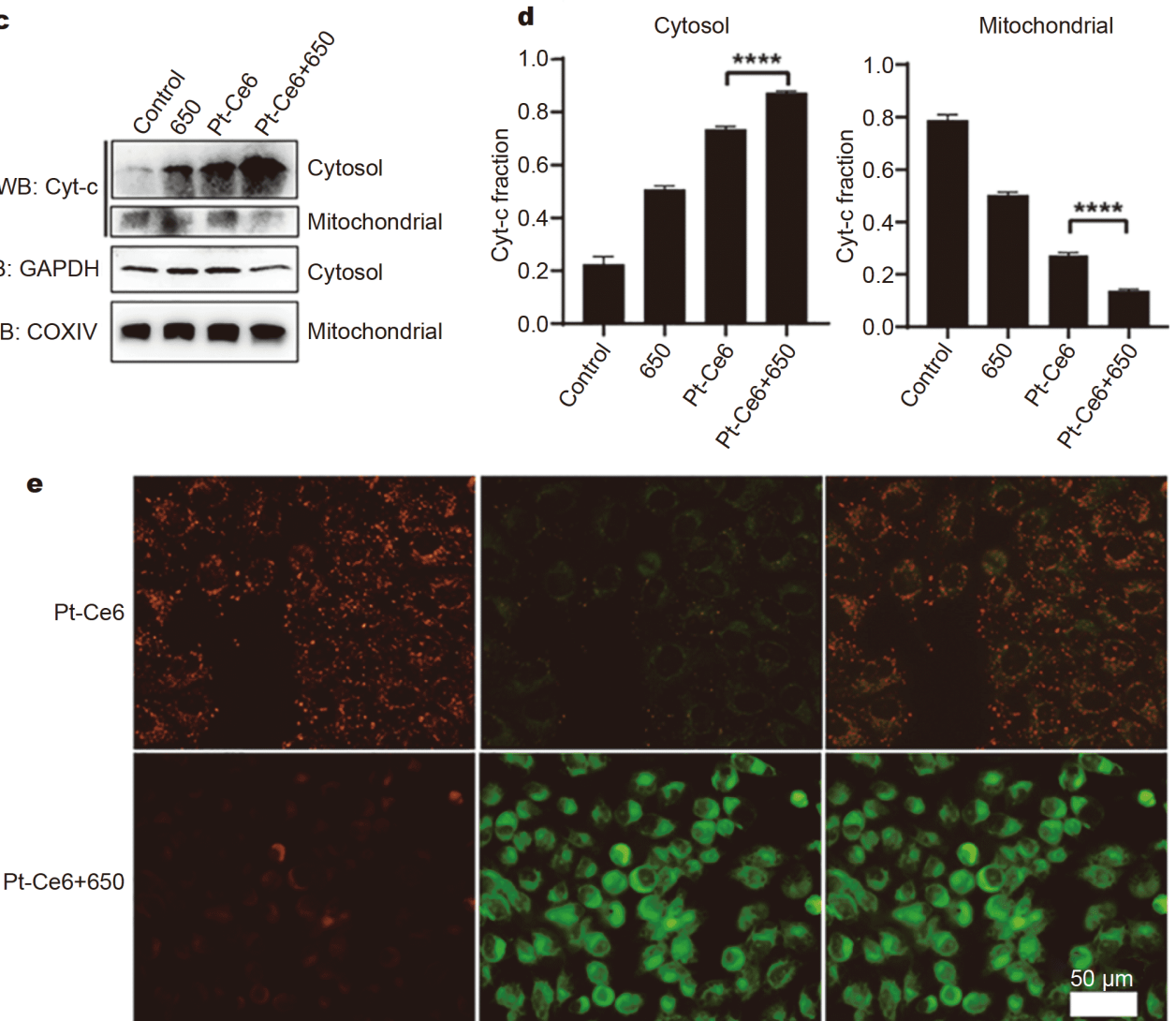

Aggregates

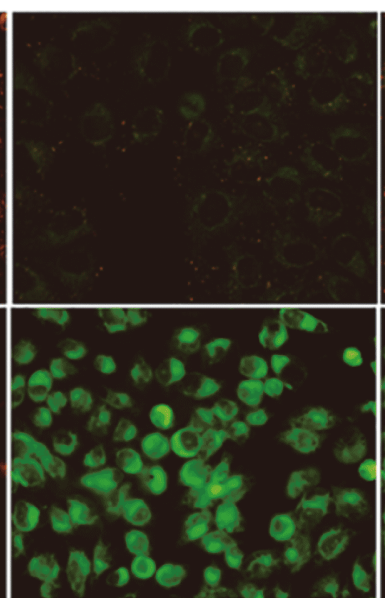

Monomer

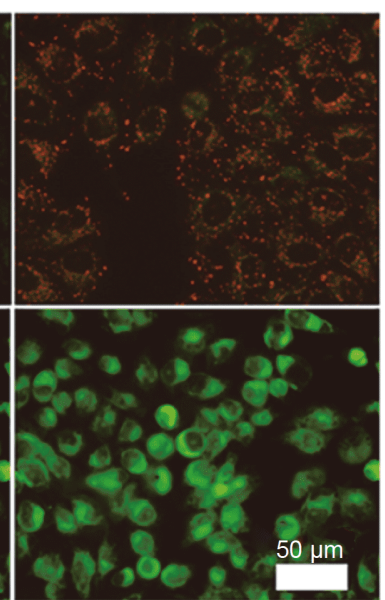

Merge

Figure 8 Pt-Ce6-mediated PDT induced apoptosis in HeLa cells through mitochondrial pathway. (a) Expression of Bcl-2 family proteins Bax and Bcl2 by Western blot using HeLa cells treated with Pt-Ce6-mediated PDT $(650 \mathrm{~nm})$. GAPDH was served as internal control. (b) Quantitative analysis of the relative ratio of Bax/Bcl-2 shown in Western blot (a). (c) Expression of cytosol and mitochondrial Cyt-c by Western blot using HeLa cells treated with Pt-Ce6-mediated PDT (650 nm). GAPDH and COX IV were served as cytosol and mitochondrial internal controls, respectively. (d) Quantitative analysis of the relative Cyt-c protein levels shown in Western blot (c). (e) Measurement of MMP of HeLa cells treated with Pt-Ce6-mediated PDT $(650 \mathrm{~nm})$ by JC-1 staining assay. The $p$ values in $(\mathrm{b}, \mathrm{d})$ were calculated by Tukey's posttest $\left(\stackrel{* * * *}{p} p<0.0001,{ }^{* * *} p<0.001\right)$.

As shown in Fig. 8e, a high MMP was maintained in HeLa cells that were incubated with Pt-Ce6 only. However, after PDT treatment, the red fluorescence intensity of JC-1 aggregates was significantly weakened while the green fluorescence of JC-1 monomers was enhanced, indicating the depolarization of mitochondrial mem- 
brane. Overall, these results showed that Pt-Ce6-mediated PDT induced apoptosis of cancer cells through mitochondria-mediated pathway.

\section{In vitro PTT and synergistic PTT/PDT effects of Pt-Ce6} For PTT, two basic requirements need to be met in order to achieve effective tumor ablation, one is to minimize the scattering and absorption of tissue to obtain effective light penetration and minimize the self-heating of tissue, and the other is the high photothermal conversion efficiency of PTAs [44]. In view of the following reasons: (i) $1064 \mathrm{~nm}$ laser has a larger MPE $\left(1 \mathrm{~W} \mathrm{~cm}^{-2}\right)$, deeper penetration depth and lower tissue self-heating; (ii) the prepared Pt-Ce6 has higher photothermal conversion efficiency at $1064 \mathrm{~nm}$ (NIR-II, 52.62\%) than that at $808 \mathrm{~nm}$ (NIR-I, 39.06\%, Fig. 4f). We chose $1064 \mathrm{~nm}$ laser as the light source to investigate the PTT effect of Pt-Ce6 in HeLa cells. As shown in Fig. 9a, a dose-dependent cytotoxicity of Pt-Ce6 was observed after irradiation at $1064 \mathrm{~nm}$. When Pt-Ce6 reached $160 \mu \mathrm{g} \mathrm{mL}^{-1}$, the cell vitality was only about $30 \%$ after $1064 \mathrm{~nm}$ laser excitation, which was in sharp contrast to laser irradiation alone. In addition, we also found that protein level of molecule chaperone Hsp90 was elevated after Pt-Ce6-mediated PTT, which might exert protective effect in response to cellular stress (Fig. S8a and b).

Next, we tried to investigate the combination effect of PDT and PTT. HeLa cells treated with Pt-Ce6 were exposed to $1064 \mathrm{~nm}$ laser irradiation $\left(1 \mathrm{~W} \mathrm{~cm}^{-2}\right)$ for $10 \mathrm{~min}$ and $650 \mathrm{~nm}\left(0.15 \mathrm{~W} \mathrm{~cm}^{-2}\right)$ for $5 \mathrm{~min}$. The outcomes magnified that the viability of HeLa cells was merely affected by laser irradiation $(1064 \mathrm{~nm}+650 \mathrm{~nm})$ alone (Fig. 9a). Exposure to laser at 650 or $1064 \mathrm{~nm}$ caused a remarkable reduction in viability of Pt-Ce6 treated cells. Importantly, exposure to both lasers led to the minimal viability at any concentration of Pt-Ce6 tested. Microscopic images of HeLa cells stained with calcein AM and PI also confirmed the results (Fig. 9b). In addition, we observed that some HeLa cells died after irradiation at $1064 \mathrm{~nm}$ for only $5 \mathrm{~min}$ while more cells died with the prolonged duration of laser exposure (Fig. S9). Thus, the potential synergy between PDT and PTT confers Pt-Ce6 nanocomposite optimal cell killing ability as compared with PDT or PTT alone.
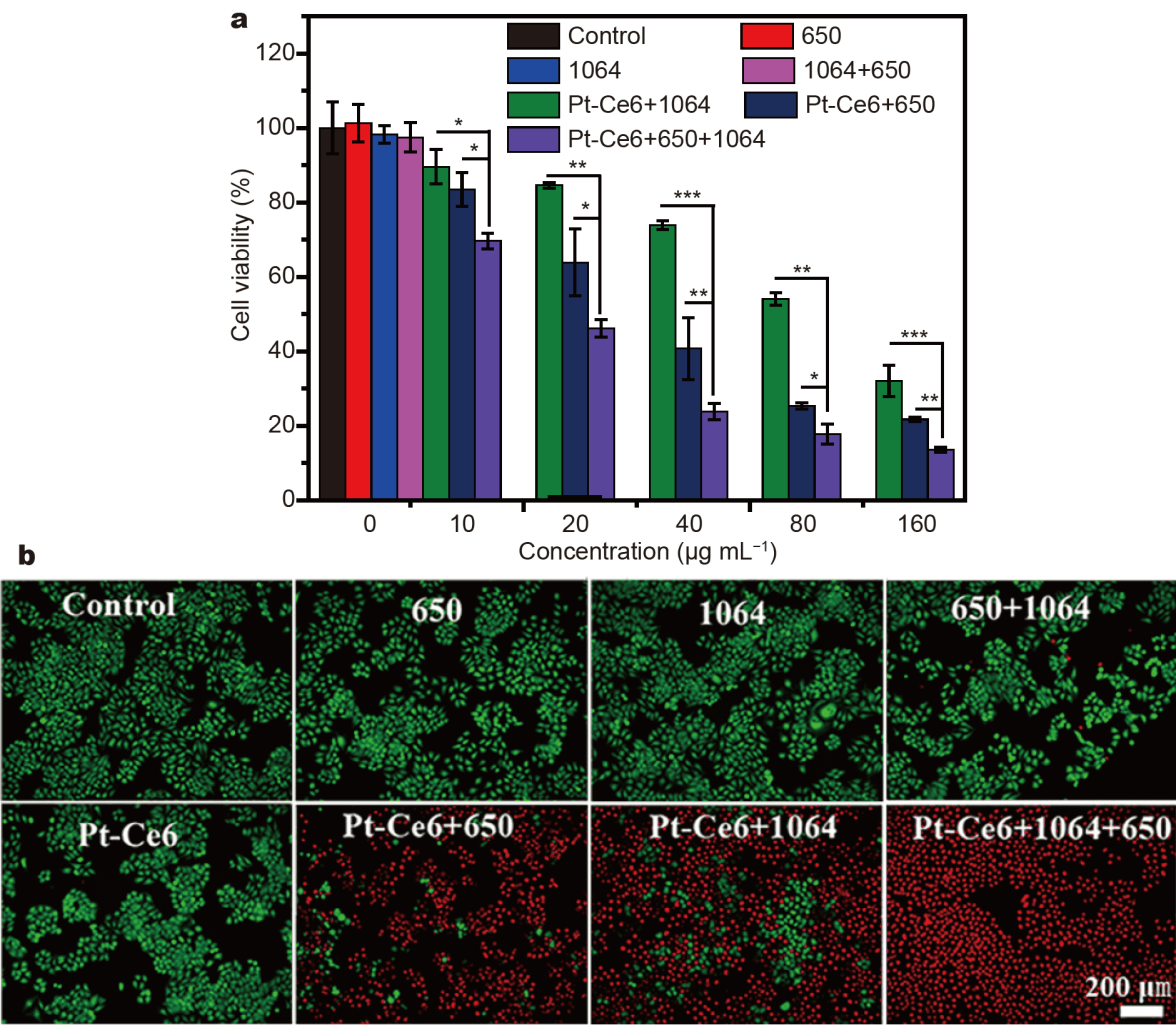

Figure 9 Pt-Ce6-mediated PDT and PTT synergistically induced cell death in HeLa cells. Cell viabilities (a) and the corresponding microscopy images (b) of HeLa cells stained with calcein AM/PI after different treatments. The $p$ values in (a) were calculated by Tukey's posttest $\left({ }^{* * *} p<0.001,{ }^{* *} p<\right.$ 0.01 , or $\left.{ }^{*} p<0.05\right)$. 


\section{Biosafety evaluation and antitumor efficacy of Pt-Ce6 in vivo}

In order to ensure the safety of Pt-Ce6 in biological applications, the in vivo toxicology was systematically studied. First, the potential toxicity of nanocomposites to organs was assessed using serum biochemical analysis. The levels of aspartate aminotransferase (AST), alanine aminotransferase (ALT), and alkaline phosphatase (ALP) reflect the condition of the liver. Creatinine (CREA) and blood urea nitrogen (BUN) can reflect the health of the kidneys. Compared with the control group, the above indexes in the Pt-Ce6 treatment group were not significantly abnormal, indicating that liver and kidney functions were normal and Pt-Ce6 had no obvious toxicity or side effects on these two organs. In addition, standard hematological parameters such as red blood cell (RBC) count, hematocrit (HCT), hemoglobin (HGB) concentration, mean red blood cell volume (MCV), mean hemoglobin content $(\mathrm{MCH})$, and mean corpuscular hemoglobin concentration (MCHC) were also examined (Fig. S10). Compared with the control group, none of the indicators in the Pt-Ce6 treatment group were abnormal, proving that no significant infection or inflammation occurred throughout the treatment period. In addition, Pt-Ce6 had no significant effect on the body weight of mice (Fig. 10a). Finally, H\&E staining was performed with the primary organs of the mice such as the heart, liver, spleen, lung, and kidney (Fig. S11). After 14 days post-injection, no significant lesions were observed in the main organs, indicating that the Pt-Ce6 nanocomposites have good histocompatibility. In view of the above biosafety evaluation outcomes, we can judge that Pt-Ce6 nanocomposite has good biocompatibility and is anticipated to be used in the combination of PDT/PTT of cancer.

Additionally, we further explored the accumulation of PtCe6 in tumors. The biodistribution showed that PtCe6 was mainly accumulated in the liver and spleen (reticuloendothelial system), approximately $29 \% \mathrm{ID} \mathrm{g}^{-1}$ and $16 \% \mathrm{ID} \mathrm{g}^{-1}$, respectively. However, Pt-Ce6 also demonstrated higher tumor enrichment, reaching $19 \% \mathrm{ID} \mathrm{g}^{-1}$ after $24 \mathrm{~h}$ (Fig. S12), which proved that the nanocomposites can be accumulated at the tumor location through the EPR effect. This provides a strong guarantee for its good treatment effect in solid tumors.

In view of the high synergistic PDT/PTT effect of PtCe6 in vitro, in vivo anti-tumor experiments were further evaluated. Tumor-bearing mice were randomly divided into seven groups $(n=5)$ and treated as follows: (1) control, (2) 650+1064 nm laser, (3) Pt-Ce6, (4) Ce6+
650 nm laser, (5) Pt-Ce6+650 nm laser, (6) Pt-Ce6+ $1064 \mathrm{~nm}$ laser, and (7) Pt-Ce6+650+1064 nm laser. After $24 \mathrm{~h}$ of intravenous injection, different treatments were given to each group. The exposure doses of the 650 and $1064 \mathrm{~nm}$ lasers were $0.15 \mathrm{~W} \mathrm{~cm}^{-2}, 5 \mathrm{~min}$, and $1 \mathrm{~W} \mathrm{~cm}^{-2}$, $5 \mathrm{~min}$, respectively. Next, the tumor volume of each group was measured and recorded every two days, and the curve of tumor volume with time was plotted, as shown in Fig. 10b. As we expected, for the groups of untreated, irradiation or Pt-Ce6 alone, there were no significant inhibitory effect on the growth of tumor. The other groups have different degrees of inhibition on tumor growth. The group of Pt-Ce6+650 nm has a more pronounced inhibitory effect than the group of $\mathrm{Ce} 6+$ $650 \mathrm{~nm}$ laser. This is mainly due to the efficient targeting of Pt-Ce6 nanocomposites based on the EPR effect and the excellent ability to catalyze the decomposition of $\mathrm{H}_{2} \mathrm{O}_{2}$ to $\mathrm{O}_{2}$. The group of Pt-Ce6+1064 nm laser also showed an inhibitory effect on tumor growth with a slight increase in tumor volume throughout the treatment period. The group of Pt-Ce6+650+1064 nm laser has a strongest inhibitory effect on tumor growth. Remarkably, after the combination of PTT and PDT, the tumor almost completely melted without recurrence. This further confirms that the combined photothermal and photodynamic therapy is more effective than either of single treatment. In addition, there was no significant weight loss or fluctuation in each group after treatment (Fig. 10a), which proved that all treatments had negligible side effects. Further H\&E staining of the main organs confirmed the high histocompatibility of Pt-Ce6 (Fig. S13). The representative tumor photos at the 14th day after treatment also confirmed the above results (Fig. 10c). These results indicate that based on the excellent catalytic capacity and photothermal conversion ability of Pt-Ce6, enhanced PDT and high-efficiency PTT are effectively integrated, and their synergistic treatment effect is better than single PDT or PTT treatment. In addition, H\&E and TUNEL staining of tumor tissues further demonstrated that PtCe6 nanocomposite mediated PDT and PTT could lead to severe apoptosis of tumor cells (Fig. 10e and f). The CATlike activity of the $\mathrm{Pt}-\mathrm{Ce} 6$ can catalyze the decomposition of endogenous $\mathrm{H}_{2} \mathrm{O}_{2}$ and generate oxygen in situ, which is expected to significantly relieve the hypoxic environment of the solid tumor and increase the oxygen content in the tumor. To prove the ability of $\mathrm{Pt}-\mathrm{Ce} 6$ to mitigate tumor hypoxia, HIF-1a immunofluorescence staining (green) was performed on tumors extracted from mice. Pt-Ce6 caused significant down-regulation of HIF-1 $\alpha$, indicating that tumor hypoxia was successfully alleviated. In con- 
a
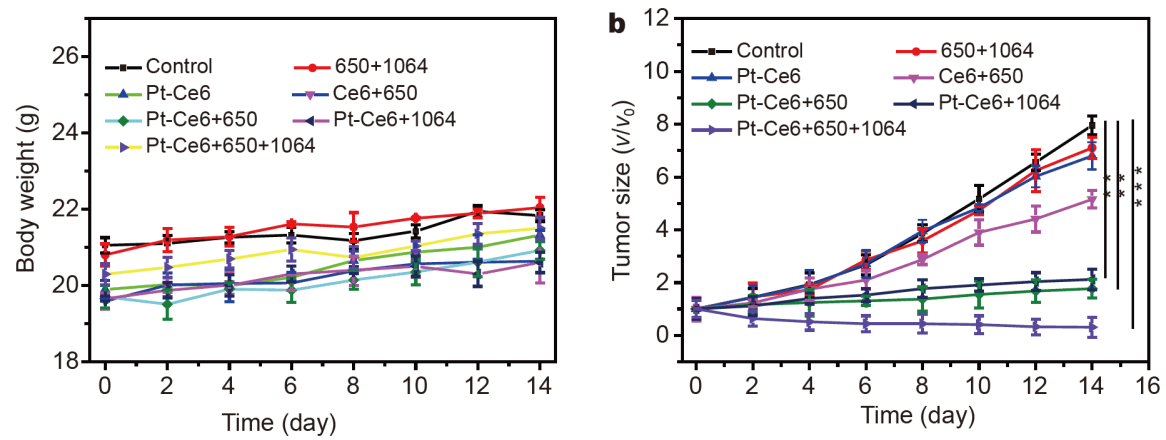

Control

$650+1064$

Ce6+650 Pt-Ce6

c

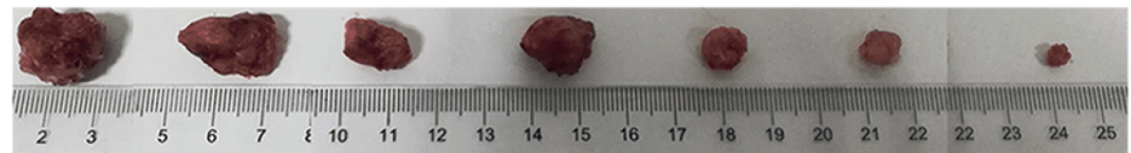

d

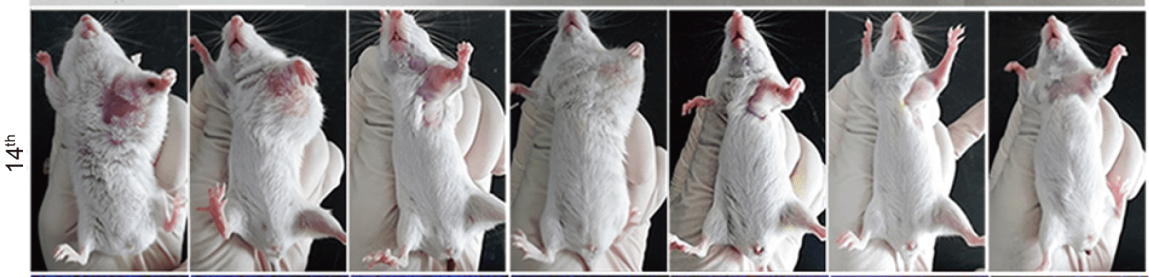

e
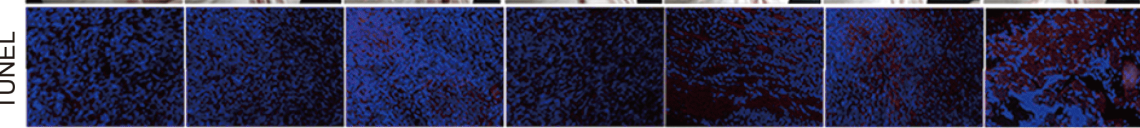

f
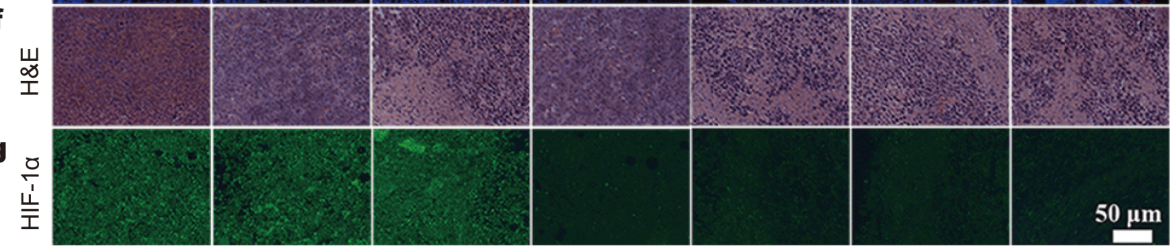

Figure 10 Changes in weight (a) and tumor volume (b) in mice treated with different methods. Digital pictures of tumors (c) and mice (d) at the 14th day after treatment. TUNEL staining (e) and H\&E staining (f) of tumor tissues at the 14th day. The nuclei and apoptotic cells were stained blue (DAPI staining) and red (TUNEL staining). (g) A representative immunofluorescent image of tumor slices stained with HIF-1 $\alpha$. The $p$ values in (a) were calculated by Tukey's posttest $\left({ }^{* * *} p<0.001,{ }^{* *} p<0.01\right)$.

trast, HIF-1a remained virtually unchanged in tumor tissue in the free Ce6 treatment group (Fig. 10g). Therefore, our studies demonstrated that Pt-Ce6 nanocomposites could alleviate tumor hypoxia and improve the therapeutic effectiveness of PDT and PTT within the hypoxic tumor region.

\section{Photothermal and CT imaging}

After intratumoral injection of Pt-Ce6, tumor-bearing mice were anesthetized, and then the tumor site was exposed to a 1064-nm laser for $5 \mathrm{~min}$. During laser irradiation, the temperature of the tumor site rapidly increased from 37.2 to $56.3^{\circ} \mathrm{C}$. In sharp contrast, the tumor temperature of mice injected with saline showed a very slight increase under the same laser power density illumination (Fig. 11a, b). Taking into account the high absorption coefficient of Pt by X-rays [67], we also evaluated the potential of Pt-Ce6 nanocomposites as CT contrast agent. As shown in Fig. 11c, the CT value increases and shows a linear trend as the concentration increases. The slope of the CT value of Pt-Ce6 (38.55 $\mathrm{HU} \mathrm{L} \mathrm{g}^{-1}$ ) was calculated, which is much higher than those of the clinical CT contrast agents iopromide (16.38 $\mathrm{HU} \mathrm{L} \mathrm{g}^{-1}$ ) and iobitridol (25.63 $\mathrm{HU} \mathrm{L} \mathrm{g}^{-1}$ ) [68]. Next, the feasibility of Pt-Ce6 in CT imaging of living animals is further discussed. As seen from Fig. 11d, the CT signal of the tumor after Pt-Ce6 intratumor injection is obvious, indicating that $\mathrm{Pt}-\mathrm{Ce} 6$ has significant potential 

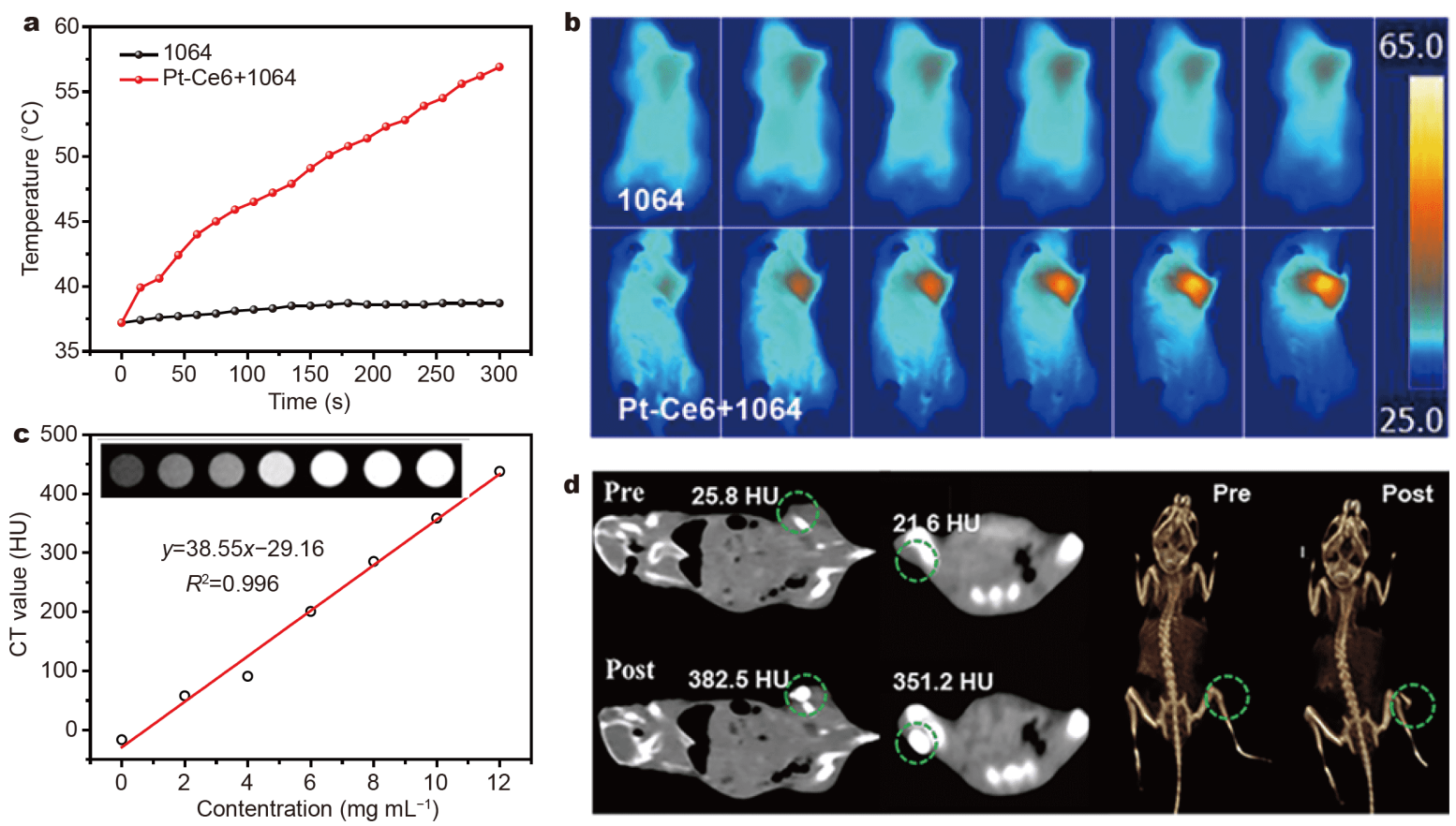

Figure $11(\mathrm{a}, \mathrm{b})$ The time-dependent temperature changes and infrared thermal imaging of tumor sites in tumor-bearing mice after different treatments. (c) CT images (above) and HU values of the Pt-Ce6 with different concentrations. (d) CT images in different directions and tomographic reconstruction images before and after intratumoral injection of Pt-Ce6.

as a CT contrast agent.

\section{CONCLUSIONS}

In conclusion, Pt-Ce6 nanocomposites were constructed by a simple and repeatable method. Excellent CAT activity, photothermal conversion efficiency and stability enable Pt-Ce6 to be used as a natural CAT mimic and NIR-II photothermal reagent for enhanced PDT and PTT synergistic therapy. Pt-Ce6-mediated PDT induces cell death through apoptosis and is related to the disruption of mitochondrial function. No significant side effects or tissue damage were found in in vitro or in vivo toxicity tests. Systematic studies of Pt-Ce6 nanocomposites for PDT/PTT synergistic therapy are provided, which will facilitate future clinical studies of platinum-based nanomaterials in cancer therapy.

Received 13 April 2020; accepted 13 June 2020; published online 9 September 2020

1 Liu JN, Bu W, Shi J. Chemical design and synthesis of functionalized probes for imaging and treating tumor hypoxia. Chem Rev, 2017, 117: 6160-6224

2 Yang G, Phua SZF, Lim WQ, et al. A hypoxia-responsive albuminbased nanosystem for deep tumor penetration and excellent therapeutic efficacy. Adv Mater, 2019, 31: 1901513

3 Huang Y, Ren J, Qu X. Nanozymes: Classification, catalytic me- chanisms, activity regulation, and applications. Chem Rev, 2019, 119: 4357-4412

4 Li Y, Yun KH, Lee H, et al. Porous platinum nanoparticles as a high- $\mathrm{Z}$ and oxygen generating nanozyme for enhanced radiotherapy in vivo. Biomaterials, 2019, 197: 12-19

5 Yang Y, Chen M, Wang B, et al. NIR-II driven plasmon-enhanced catalysis for a timely supply of oxygen to overcome hypoxiainduced radiotherapy tolerance. Angew Chem Int Ed, 2019, 58: 15069-15075

6 Nakajima T, Sano K, Mitsunaga M, et al. Real-time monitoring of in vivo acute necrotic cancer cell death induced by near infrared photoimmunotherapy using fluorescence lifetime imaging. Cancer Res, 2012, 72: 4622-4628

7 Nakajima T, Sano K, Choyke PL, et al. Improving the efficacy of Photoimmunotherapy (PIT) using a cocktail of antibody conjugates in a multiple antigen tumor model. Theranostics, 2013, 3: 357-365

8 Hou Z, Deng K, Wang M, et al. Hydrogenated titanium oxide decorated upconversion nanoparticles: Facile laser modified synthesis and $808 \mathrm{~nm}$ near-infrared light triggered phototherapy. Chem Mater, 2019, 31: 774-784

9 Feng $\mathrm{Y}, \mathrm{Wu} \mathrm{Y}$, Zuo J, et al. Assembly of upconversion nanophotosensitizer in vivo to achieve scatheless real-time imaging and selective photodynamic therapy. Biomaterials, 2019, 201: 33-41

10 Bi H, He F, Dai Y, et al. Quad-model imaging-guided high-efficiency phototherapy based on upconversion nanoparticles and $\mathrm{ZnFe}_{2} \mathrm{O}_{4}$ integrated graphene oxide. Inorg Chem, 2018, 57: 99889998

11 Liu B, Li C, Yang P, et al. 808-nm-light-excited lanthanide-doped nanoparticles: Rational design, luminescence control and ther- 
anostic applications. Adv Mater, 2017, 29: 1605434

12 Ge X, Song ZM, Sun L, et al. Lanthanide $\left(\mathrm{Gd}^{3+}\right.$ and $\left.\mathrm{Yb}^{3+}\right)$ functionalized gold nanoparticles for in vivo imaging and therapy. Biomaterials, 2016, 108: 35-43

13 Dang J, He H, Chen D, et al. Manipulating tumor hypoxia toward enhanced photodynamic therapy (PDT). Biomater Sci, 2017, 5: 1500-1511

14 Wei J, Li J, Sun D, et al. A novel theranostic nanoplatform based on Pd@Pt-PEG-Ce6 for enhanced photodynamic therapy by modulating tumor hypoxia microenvironment. Adv Funct Mater, 2018, 28: 1706310

15 Cheng Y, Cheng H, Jiang C, et al. Perfluorocarbon nanoparticles enhance reactive oxygen levels and tumour growth inhibition in photodynamic therapy. Nat Commun, 2015, 6: 8785

16 Song G, Liang C, Yi X, et al. Perfluorocarbon-loaded hollow $\mathrm{Bi}_{2} \mathrm{Se}_{3}$ nanoparticles for timely supply of oxygen under near-infrared light to enhance the radiotherapy of cancer. Adv Mater, 2016, 28: 27162723

17 Chen J, Luo H, Liu Y, et al. Oxygen-self-produced nanoplatform for relieving hypoxia and breaking resistance to sonodynamic treatment of pancreatic cancer. ACS Nano, 2017, 11: 12849-12862

18 Yu Z, Zhou P, Pan W, et al. A biomimetic nanoreactor for synergistic chemiexcited photodynamic therapy and starvation therapy against tumor metastasis. Nat Commun, 2018, 9: 5044

19 Lu N, Fan W, Yi X, et al. Biodegradable hollow mesoporous organosilica nanotheranostics for mild hyperthermia-induced bubble-enhanced oxygen-sensitized radiotherapy. ACS Nano, 2018, 12: 1580-1591

20 Huang CC, Chia WT, Chung MF, et al. An implantable depot that can generate oxygen in situ for overcoming hypoxia-induced resistance to anticancer drugs in chemotherapy. J Am Chem Soc, 2016, 138: 5222-5225

21 Sheng Y, Nesbitt H, Callan B, et al. Oxygen generating nanoparticles for improved photodynamic therapy of hypoxic tumours. J Control Release, 2017, 264: 333-340

22 Prasad P, Gordijo CR, Abbasi AZ, et al. Multifunctional albumin$\mathrm{MnO}_{2}$ nanoparticles modulate solid tumor microenvironment by attenuating hypoxia, acidosis, vascular endothelial growth factor and enhance radiation response. ACS Nano, 2014, 8: 3202-3212

23 Fan $\mathrm{W}, \mathrm{Bu} \mathrm{W}$, Shen $\mathrm{B}$, et al. Intelligent $\mathrm{MnO}_{2}$ nanosheets anchored with upconversion nanoprobes for concurrent $\mathrm{pH}-/ \mathrm{H}_{2} \mathrm{O}_{2}$-responsive UCL imaging and oxygen-elevated synergetic therapy. Adv Mater, 2015, 27: 4155-4161

24 Zheng DW, Li B, Li CX, et al. Carbon-dot-decorated carbon nitride nanoparticles for enhanced photodynamic therapy against hypoxic tumor via water splitting. ACS Nano, 2016, 10: 8715-8722

25 Zhang T, Jiang Z, Chen L, et al. PCN-Fe(III)-PTX nanoparticles for MRI guided high efficiency chemo-photodynamic therapy in pancreatic cancer through alleviating tumor hypoxia. Nano Res, 2020, 13: 273-281

26 Zhang $\mathrm{C}$, Chen WH, Liu LH, et al. An $\mathrm{O}_{2}$ self-supplementing and reactive-oxygen-species-circulating amplified nanoplatform via $\mathrm{H}_{2} \mathrm{O} / \mathrm{H}_{2} \mathrm{O}_{2}$ splitting for tumor imaging and photodynamic therapy. Adv Funct Mater, 2017, 27: 1700626

27 Wang $\mathrm{D}, \mathrm{Wu} \mathrm{H}, \mathrm{Lim} \mathrm{WQ}$, et al. A mesoporous nanoenzyme derived from metal-organic frameworks with endogenous oxygen generation to alleviate tumor hypoxia for significantly enhanced photodynamic therapy. Adv Mater, 2019, 31: 1901893

28 Wang XS, Zeng JY, Zhang MK, et al. A versatile pt-based core-shell nanoplatform as a nanofactory for enhanced tumor therapy. Adv
Funct Mater, 2018, 28: 1801783

29 Tsai MF, Chang SHG, Cheng FY, et al. Au nanorod design as lightabsorber in the first and second biological near-infrared windows for in vivo photothermal therapy. ACS Nano, 2013, 7: 5330-5342

30 Hu J, Wang J, Tang W, et al. PEGylated polypyrrole-gold nanocomplex as enhanced photothermal agents against tumor cells. J Mater Sci, 2020, 55: 5587-5599

31 Liang M, Yan X. Nanozymes: From new concepts, mechanisms, and standards to applications. Acc Chem Res, 2019, 52: 2190-2200

32 Wu J, Wang X, Wang Q, et al. Nanomaterials with enzyme-like characteristics (nanozymes): Next-generation artificial enzymes (II). Chem Soc Rev, 2019, 48: 1004-1076

33 Liu C, Luo L, Zeng L, et al. Porous gold nanoshells on functional $\mathrm{NH}_{2}$-MOFs: Facile synthesis and designable platforms for cancer multiple therapy. Small, 2018, 14: 1801851

34 Liu C, Xing J, Akakuru OU, et al. Nanozymes-engineered metalorganic frameworks for catalytic cascades-enhanced synergistic cancer therapy. Nano Lett, 2019, 19: 5674-5682

35 Li S, Gu K, Wang H, et al. Degradable holey palladium nanosheets with highly active 1D nanoholes for synergetic phototherapy of hypoxic tumors. J Am Chem Soc, 2020, 142: 5649-5656

36 Zhang L, Liu C, Gao Y, et al. ZD2-engineered gold nanostar@metal-organic framework nanoprobes for $\mathrm{T}_{1}$-weighted magnetic resonance imaging and photothermal therapy specifically toward triple-negative breast cancer. Adv Healthcare Mater, 2018, 7: 1801144

37 Zhu XM, Wan HY, Jia $\mathrm{H}$, et al. Porous Pt nanoparticles with high near-infrared photothermal conversion efficiencies for photothermal therapy. Adv Healthcare Mater, 2016, 5: 3165-3172

38 Cheng $\mathrm{H}$, Huo D, Zhu C, et al. Combination cancer treatment through photothermally controlled release of selenous acid from gold nanocages. Biomaterials, 2018, 178: 517-526

39 Wang D, Liu B, Quan Z, et al. New advances on the marrying of UCNPs and photothermal agents for imaging-guided diagnosis and the therapy of tumors. J Mater Chem B, 2017, 5: 2209-2230

40 Ding B, Yu C, Li C, et al. Cis-platinum pro-drug-attached $\mathrm{CuFeS}_{2}$ nanoplates for in vivo photothermal/photoacoustic imaging and chemotherapy/photothermal therapy of cancer. Nanoscale, 2017, 9: 16937-16949

41 Zhang L, Chen Y, Li Z, et al. Tailored synthesis of octopus-type Janus nanoparticles for synergistic actively-targeted and chemophotothermal therapy. Angew Chem Int Ed, 2016, 55: 2118-2121

42 Chang $M$, Wang $M$, Wang $M$, et al. A multifunctional cascade bioreactor based on hollow-structured $\mathrm{Cu}_{2} \mathrm{MoS}_{4}$ for synergetic cancer chemo-dynamic therapy/starvation therapy/phototherapy/ immunotherapy with remarkably enhanced efficacy. Adv Mater, 2019, 31: 1905271

43 Wang $\mathrm{F}$, Wen $\mathrm{S}, \mathrm{He} \mathrm{H}$, et al. Microscopic inspection and tracking of single upconversion nanoparticles in living cells. Light Sci Appl, 2018, 7: 18007

44 Tang Z, Zhao P, Ni D, et al. Pyroelectric nanoplatform for NIR-IItriggered photothermal therapy with simultaneous pyroelectric dynamic therapy. Mater Horiz, 2018, 5: 946-952

45 Zhang H, Zeng W, Pan C, et al. SnTe@ $\mathrm{MnO}_{2}$-SP nanosheet-based intelligent nanoplatform for second near-infrared light-mediated cancer theranostics. Adv Funct Mater, 2019, 29: 1903791

46 Sun T, Han J, Liu S, et al. Tailor-made semiconducting polymers for second near-infrared photothermal therapy of orthotopic liver cancer. ACS Nano, 2019, 13: 7345-7354

47 Rastinehad AR, Anastos H, Wajswol E, et al. Gold nanoshell-lo- 
calized photothermal ablation of prostate tumors in a clinical pilot device study. Proc Natl Acad Sci USA, 2019, 116: 18590-18596

48 Wen M, Ouyang J, Wei C, et al. Artificial enzyme catalyzed cascade reactions: Antitumor immunotherapy reinforced by NIR-II light. Angew Chem Int Ed, 2019, 58: 17425-17432

49 Wang X, Ma Y, Sheng X, et al. Ultrathin polypyrrole nanosheets via space-confined synthesis for efficient photothermal therapy in the second near-infrared window. Nano Lett, 2018, 18: 2217-2225

50 Guo B, Sheng Z, Hu D, et al. Through scalp and skull NIR-II photothermal therapy of deep orthotopic brain tumors with precise photoacoustic imaging guidance. Adv Mater, 2018, 30: 1802591

51 Wang M, Wang D, Chen Q, et al. Recent advances in glucoseoxidase-based nanocomposites for tumor therapy. Small, 2019, 15: 1903895

52 Chen G, Qiu H, Prasad PN, et al. Upconversion nanoparticles: Design, nanochemistry, and applications in theranostics. Chem Rev, 2014, 114: 5161-5214

53 Yang D, Ma P, Hou Z, et al. Current advances in lanthanide ion $\left(\mathrm{Ln}^{3+}\right)$-based upconversion nanomaterials for drug delivery. Chem Soc Rev, 2015, 44: 1416-1448

54 Liu J, Liu Y, Bu W, et al. Ultrasensitive nanosensors based on upconversion nanoparticles for selective hypoxia imaging in vivo upon near-infrared excitation. J Am Chem Soc, 2014, 136: 9701-9709

55 Hou Z, Zhang Y, Deng K, et al. UV-emitting upconversion-based $\mathrm{TiO}_{2}$ photosensitizing nanoplatform: Near-infrared light mediated in vivo photodynamic therapy via mitochondria-involved apoptosis pathway. ACS Nano, 2015, 9: 2584-2599

56 Webb BA, Chimenti M, Jacobson MP, et al. Dysregulated pH: A perfect storm for cancer progression. Nat Rev Cancer, 2011, 11: 671-677

57 Wang Z, Zhang Y, Ju E, et al. Biomimetic nanoflowers by selfassembly of nanozymes to induce intracellular oxidative damage against hypoxic tumors. Nat Commun, 2018, 9: 3334

58 Zeng J, Goldfeld D, Xia Y. A plasmon-assisted optofluidic (PAOF) system for measuring the photothermal conversion efficiencies of gold nanostructures and controlling an electrical switch. Angew Chem Int Ed, 2013, 52: 4169-4173

59 Tian Q, Jiang F, Zou R, et al. Hydrophilic $\mathrm{Cu}_{9} \mathrm{~S}_{5}$ nanocrystals: A photothermal agent with a $25.7 \%$ heat conversion efficiency for photothermal ablation of cancer cells in vivo. ACS Nano, 2011, 5: 9761-9771

60 Cai X, Jia X, Gao W, et al. A versatile nanotheranostic agent for efficient dual-mode imaging guided synergistic chemo-thermal tumor therapy. Adv Funct Mater, 2015, 25: 2520-2529

61 Lin H, Gao S, Dai C, et al. A two-dimensional biodegradable niobium carbide (MXene) for photothermal tumor eradication in NIR-I and NIR-II biowindows. J Am Chem Soc, 2017, 139: 1623516247

62 Wu WS. The signaling mechanism of ROS in tumor progression. Cancer Metastasis Rev, 2007, 25: 695-705

63 Cerutti PA. Prooxidant states and tumor promotion. Science, 1985, 227: $375-381$

64 Han L, Du LB, Kumar A, et al. Inhibitory effects of trolox-encapsulated chitosan nanoparticles on tert-butylhydroperoxide induced RAW264.7 apoptosis. Biomaterials, 2012, 33: 8517-8528

65 Wang L, Lu K, Hao H, et al. Decreased autophagy in rat heart induced by anti- $\beta 1$-adrenergic receptor autoantibodies contributes to the decline in mitochondrial membrane potential. PLoS ONE, 2013, 8: e81296

66 Cavalieri E, Rigo A, Bonifacio M, et al. Pro-apoptotic activity of $\alpha$ bisabolol in preclinical models of primary human acute leukemia cells. J Transl Med, 2011, 9: 45

67 Wang Q, Wang H, Yang Y, et al. Plasmonic Pt superstructures with boosted near-infrared absorption and photothermal conversion efficiency in the second biowindow for cancer therapy. Adv Mater, 2019, 31: 1904836

68 Barreto JA, O'Malley W, Kubeil M, et al. Nanomaterials: Applications in cancer imaging and therapy. Adv Mater, 2011, 23: H18$\mathrm{H} 40$

Acknowledgements This work was supported by the National Natural Science Foundation of China (51872263 and 31970755), and Zhejiang Provincial Natural Science Foundation (LZ19E020001 and LQ18B010002).

Author contributions $\quad \mathrm{Li} \mathrm{C}$ designed the study and supervised the project; Chen Q conceived the experimental scheme. Chen Q, He S, Zhang F and Wang M performed the experiments; Chen Q, He S and Wang D performed the data analyses; Cui F and Liu J carried out the CT imaging; Chen $\mathrm{Q}$ wrote the paper with support from Li C and Jin Z. All authors contributed to the general discussion.

Conflict of interest The authors declare that they have no conflict of interest.

Supplementary information Experimental details and supporting data are available in the online version of the paper. 


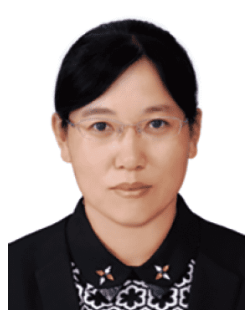

Chunxia Li received her $\mathrm{PhD}$ degree in 2008 from Changchun Institute of Applied Chemistry, Chinese Academy of Sciences under the guidance of Prof. Jun Lin. After graduation, she became an assistant professor in Prof. Lin's group and was promoted to associate professor in 2012. She worked at Zhejiang Normal University from 2016 to 2019. Now she is working as a professor at the Institute of Frontier and Interdisciplinarity Science and Institute of Molecular Sciences and Engineering, Shandong University. Her research interests focus on the controllable syntheses of multifuntional inoragnic nanomaterials and their bio-application.

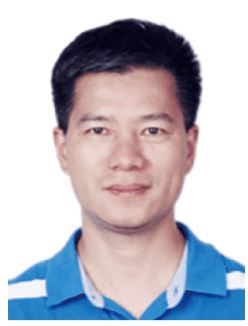

Zhigang Jin received his $\mathrm{PhD}$ degree in 2006 from the Institute of Biochemistry and Cell Biology, Shanghai Institutes for Biological Sciences, Chinese Academy of Sciences under the guidance of Prof. Naihe Jing. After graduation, he became an assistant professor in Prof. Jing's group. From 2008 to 2017, he worked as post-doc and research associate at Ohio State University and the University of Illinois at Urbana-Champaign, respectively. He has been working as professor in the College of Chemistry and Life Sciences, Zhejiang Normal University since 2017. His research interests focus on molecular mechanism during embryonic development and tumorigenesis.

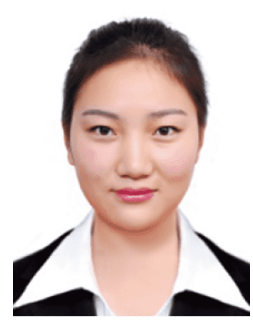

Qing Chen received her BS degree from Liaocheng University, China, in 2017. She is a postgraduate student under the supervision of Prof. Chunxia Li at Zhejiang Normal University. Her current research focuses on the syntheses and biomedical applications of inorganic nanomaterials.

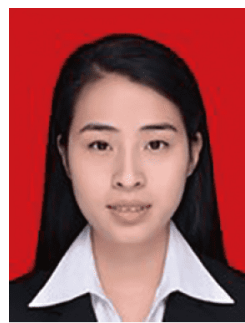

Su He received her BA degree from Shanxi Medical University, China, in 2017. She is a postgraduate student under the supervision of Prof. Zhigang Jin at Zhejiang Normal University. Her current research interests focus on the virus and stress granules.

\section{多功能Pt-Ce6纳米平台作为过氧化氢纳米酶和 NIR-II光热剂用于增强PDT/PTT肿瘤治疗}

陈晴 $^{1 \dagger}$, 何素 ${ }^{1 \dagger}$, 张方军 ${ }^{1}$, 崔凤至 ${ }^{3}$, 刘建华 ${ }^{3}$, 王曼 ${ }^{1}$, 王冬梅 ${ }^{1}$, 金志刚 ${ }^{1 *}$, 李春霞 ${ }^{1,2 *}$

摘要 实体肿瘤的缺氧严重影响着基于氧气的光动力疗法 (PDT) 的效果. 另外, 单一治疗模式通常难以达到满意的治疗效果. 为此, 我们设计合成了一种多功能纳米复合材料Pt-Ce6 用于克服肿瘤乏 氧, 实现PDT/PTT协同治疗. 在该体系中, 我们使用多孔Pt纳米粒 子作为过氧化氢纳米酶、近红外二区 (NIR-II) 光热转换剂和光敏 剂二氢卟吩e6 (Ce6)的载体, Pt-Ce6 可以持续、稳定地将 $\mathrm{H}_{2} \mathrm{O}_{2}$ 分解 成 $\mathrm{O}_{2}$, 从而减轻肿瘤缺氧, 增强PDT的效果. 在 $650 \mathrm{~nm}$ 激光照射下, Ce6产生的活性氧(ROS)会使线粒体膜电位降低, 促使细胞色素c (Cyt-c) 从线粒体释放到细胞质中, 最终导致PDT过程中线粒体介 导的细胞调亡. 此外, Pt-Ce6在NIR-II(1064 nm)具有良好的光热稳 定性和较高的光热转换效率(52.62\%). 活体实验结果表明该纳米复 合材料具有良好的生物相容性和PDT/PTT协同作用，有效抑制了 小鼠肿瘤的生长. 